\title{
The evolution of intracranial aneurysm treatment techniques and future directions
}

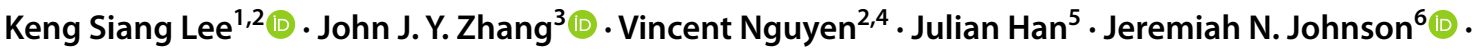 \\ Ramez Kirollos ${ }^{5,7} \cdot$ Mario Teo $^{2}$ (1)
}

Received: 13 January 2021 / Revised: 21 March 2021 / Accepted: 7 April 2021 / Published online: 23 April 2021

(c) The Author(s) 2021

\begin{abstract}
Treatment techniques and management guidelines for intracranial aneurysms (IAs) have been continually developing and this rapid development has altered treatment decision-making for clinicians. IAs are treated in one of two ways: surgical treatments such as microsurgical clipping with or without bypass techniques, and endovascular methods such as coiling, balloon- or stent-assisted coiling, or intravascular flow diversion and intrasaccular flow disruption. In certain cases, a single approach may be inadequate in completely resolving the IA and successful treatment requires a combination of microsurgical and endovascular techniques, such as in complex aneurysms. The treatment option should be considered based on factors such as age; past medical history; comorbidities; patient preference; aneurysm characteristics such as location, morphology, and size; and finally the operator's experience. The purpose of this review is to provide practicing neurosurgeons with a summary of the techniques available, and to aid decision-making by highlighting ideal or less ideal cases for a given technique. Next, we illustrate the evolution of techniques to overcome the shortfalls of preceding techniques. At the outset, we emphasize that this decision-making process is dynamic and will be directed by current best scientific evidence, and future technological advances.
\end{abstract}

Keywords Subarachnoid hemorrhage $\cdot$ Aneurysms $\cdot$ Clipping $\cdot$ Endovascular embolization $\cdot$ Coiling $\cdot$ Stents $\cdot$ Flow diversion

Keng Siang Lee and John J. Y. Zhang are co-first authors and equally contributed to this manuscript.

Keng Siang Lee

k117746@bristol.ac.uk

1 Bristol Medical School, Faculty of Health Sciences, University of Bristol, Bristol, UK

2 Department of Neurosurgery, Bristol Institute of Clinical Neuroscience, Southmead Hospital, Bristol, UK

3 Yong Loo Lin School of Medicine, National University of Singapore, Singapore, Singapore

4 Department of Neurosurgery, University of Tennessee Health Sciences Center, Memphis, TN, USA

5 Department of Neurosurgery, National Neuroscience Institute, Singapore, Singapore

6 Department of Neurosurgery, Baylor College of Medicine, Houston, TX, USA

7 Division of Neurosurgery, Department of Clinical Neurosciences, University of Cambridge and Addenbrooke's Hospital, Cambridge, UK

\section{Introduction}

Although initially thought to occur in $1-2 \%$ of the population [13], it now appears that the prevalence of intracranial aneurysms (IAs) may range between 5 and $8 \%$ [57, 61, 127], and up to $11 \%$ [19]. IAs are the leading cause of hemorrhagic stroke, accounting for $70-85 \%$ of non-traumatic subarachnoid hemorrhages (SAH) [125]. The main treatment principle includes achieving complete IA occlusion while preserving blood flow in the parent, branching, and perforating vessels. The first surgical treatment of an IA was performed in 1933 by Norman Dott [31], who wrapped a ruptured IA, while the first obliterative clipping of an IA was performed in 1938 by Walter Dandy [26]. In 1975, Yasargil and Fox described the classic microscopic assisted open approaches for IA clipping, such as the pterional craniotomy (PTC), which afforded safe and effective exposure of the circle of Willis through the Sylvian fissure with minimal retraction on the frontal and temporal lobes [134]. Indeed, with technological developments in vascular imaging, 
intraoperative navigation, and fluorescence angiography, this technique remains popular for treating IAs of the anterior circulation [77, 133].

However, the more recent advance in IA treatment has been the advent of safe and effective endovascular techniques for the treatment of IAs, particularly of the posterior circulation. Acceptance and popularity of endovascular techniques increased in 2002 with the results of the International Subarachnoid Aneurysm Trial (ISAT) [73]. Although both surgical and endovascular IA occlusion technologies are effective for appropriately selected patients, improved technology for endovascular devices and techniques has shifted the balance towards these less invasive techniques with the benefit of reduced operative time, patient preference and tolerability in less healthy patients, and decreased length of in-hospital stay [73, 93, 109-111, 113]. Nonetheless, open surgical techniques including complex IA treatment with bypass techniques remain vital in the cerebrovascular neurosurgeon's armamentarium for IAs that cannot be treated by endovascular means. The treatment techniques and management guidelines for IAs have thus continued to evolve in recent years, and these rapid developments have forced clinicians to adapt their surgical decision-making.

The purpose of this review is to provide practicing neurosurgeons with a summary of the techniques available, and to aid decision-making by highlighting ideal or less ideal cases for a given technique. Next, we illustrate the evolution of techniques to overcome the shortfalls of preceding techniques. At the outset, we emphasize that this decisionmaking process is dynamic and will be directed by current best scientific evidence, and future technological advances.

\section{Treatment strategies for IAs}

Treatment options for IAs are either surgical or endovascular, and both techniques have undergone major development in recent years, which are summarized in the following sections.

\section{Transluminal embolization techniques}

A summary of the current state of the endovascular techniques, their indications, evolution, and current limitations, is presented in Table 1 .

\section{Simple coiling}

In 1990, a detachable bare platinum coil device (Guglielmi) was introduced into clinical practice. Since then, endovascular treatment with coils has gained worldwide acceptance as an effective treatment for IAs $[10,11,73]$, and coil variations have been introduced into the market which include polymer-coated coils that incite tissue response across the IA neck, and coils coated with a hydrophilic gel that expands on exposure to blood, reducing dead space.

The goal in coiling is to achieve dense packing through the delivery of detachable platinum wires, resulting in an unorganized thrombus and granulation tissue formation, to limit blood circulation to the IA lumen. IAs are protected from rupture in ruptured $[15,73]$ and in some unruptured cases [37, 44, 132]. Clinically, packing density is recommended to be $20 \%$ or more of the IA's volume, which can require deployment of multiple coils depending on the size of the IA (Fig. 1) [78]. Online calculators are also readily available to estimate IA volumes and packing densities for various coils and IA morphologies that can help (e.g., angiocalc.com) [4].

Coiling is increasingly popular but does come with several shortcomings. Not all IAs are completely cured at first treatment necessitating post-treatment surveillance imaging and, in a minority, may require retreatment $[73,120]$. Routine follow-up imaging of a treated IA is usually performed noninvasively by either CTA or MRA. There exist no guideline and no scientific data defining the optimal regime how frequently and how long to follow-up, but generally, the frequency is dictated by the completeness and method of the original repair, as well as the other patient and IA-specific factors [107]. Another drawback of coiling is the need for retreatment due to coil compaction or IA recurrence, hence also further necessitating follow-up [15, 22, 40, 73, 95, 106, 109]. A second treatment of IAs has been reported to be around $12 \%$, on average of 27 months after the previous procedure [40]. Hence, the typical scheme would include a first follow-up scheduled 3-6 months after the endovascular procedure, followed by a 12-24-month follow-up and a midterm follow-up at 3-5 years [56]. The combination of invasiveness and radiation make digital subtraction angiography (DSA) less readily used for follow-up, but is useful to ascertain an accurate estimation of the size of the IA remnant. If not diligently followed post-treatment, ruptured IA patients treated with coiling may be at risk of delayed IA recanalization and recurrent SAH [73].

Possible determinants for initial incomplete IA occlusion and complications are unfavorable IA anatomy and vessel geometry as well as the types of coils that are used. Possible risk factors for recurrence of a coiled IA over time are large IA size [95, 123], presence of intraluminal thrombus, low packing density [49], initial incomplete occlusion [38], duration of follow-up [89], ruptured IAs, location in the posterior circulation [15], and a large neck-dome ratio [33, 47, 96].

There are several major complications associated with coil embolization: thromboembolism, perforation of the IA, early rebleeding, parent artery obstruction, collapsed coils, coil malposition, even coil migration. 


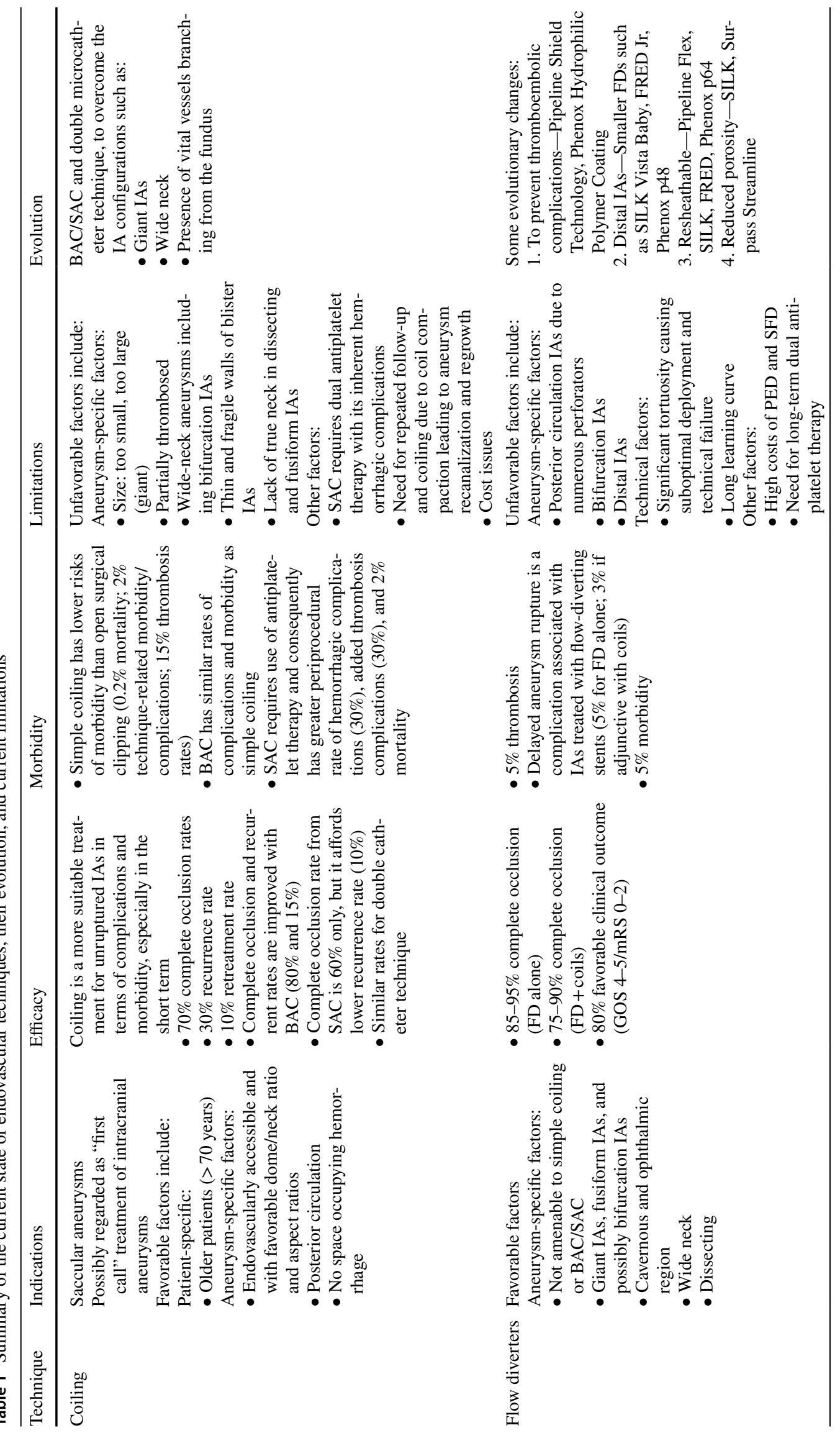



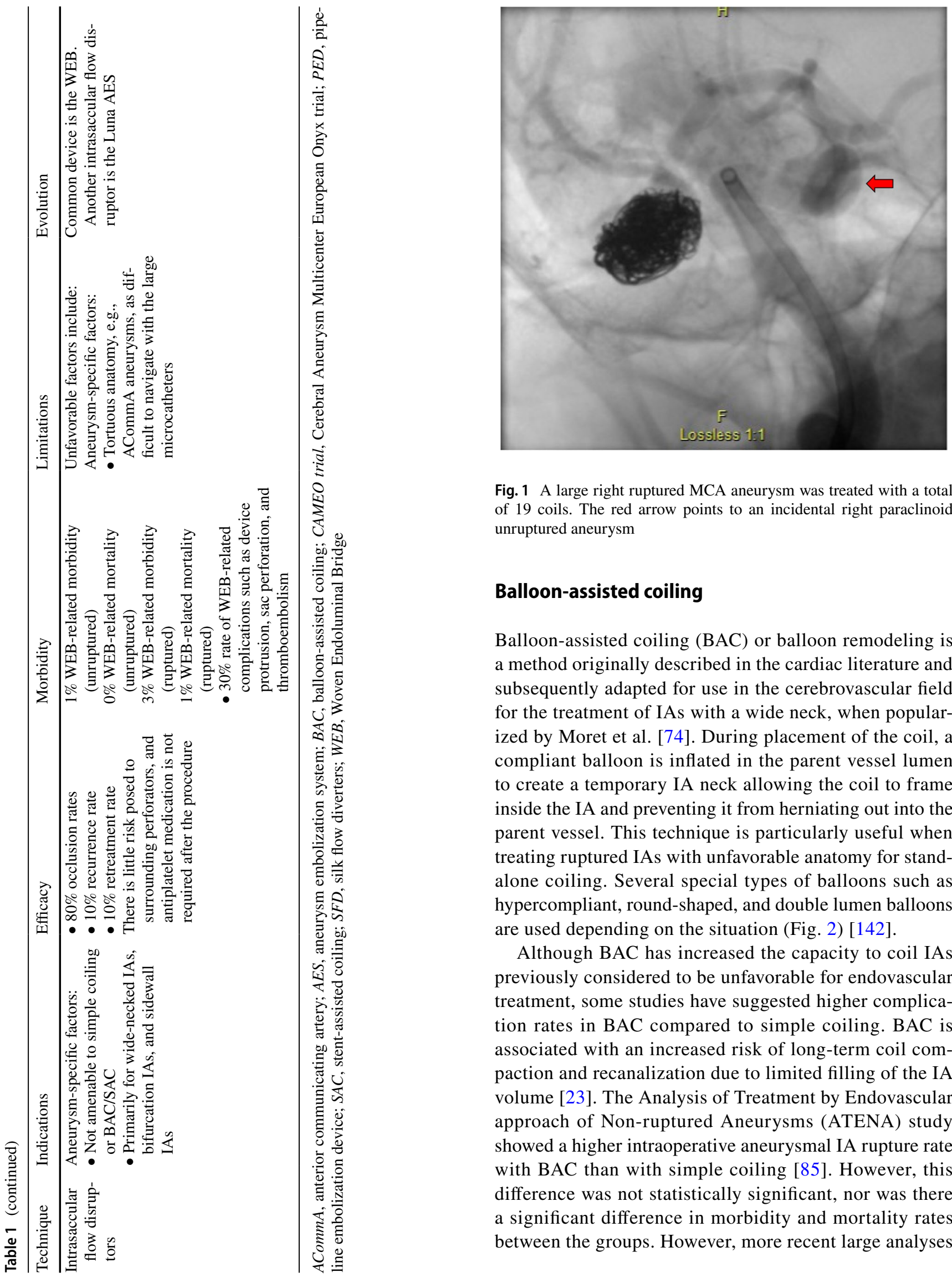

Fig. 1 A large right ruptured MCA aneurysm was treated with a total of 19 coils. The red arrow points to an incidental right paraclinoid unruptured aneurysm

\section{Balloon-assisted coiling}

Balloon-assisted coiling (BAC) or balloon remodeling is a method originally described in the cardiac literature and subsequently adapted for use in the cerebrovascular field for the treatment of IAs with a wide neck, when popularized by Moret et al. [74]. During placement of the coil, a compliant balloon is inflated in the parent vessel lumen to create a temporary IA neck allowing the coil to frame inside the IA and preventing it from herniating out into the parent vessel. This technique is particularly useful when treating ruptured IAs with unfavorable anatomy for standalone coiling. Several special types of balloons such as hypercompliant, round-shaped, and double lumen balloons are used depending on the situation (Fig. 2) [142].

Although BAC has increased the capacity to coil IAs previously considered to be unfavorable for endovascular treatment, some studies have suggested higher complication rates in BAC compared to simple coiling. BAC is associated with an increased risk of long-term coil compaction and recanalization due to limited filling of the IA volume [23]. The Analysis of Treatment by Endovascular approach of Non-ruptured Aneurysms (ATENA) study showed a higher intraoperative aneurysmal IA rupture rate with BAC than with simple coiling [85]. However, this difference was not statistically significant, nor was there a significant difference in morbidity and mortality rates between the groups. However, more recent large analyses 


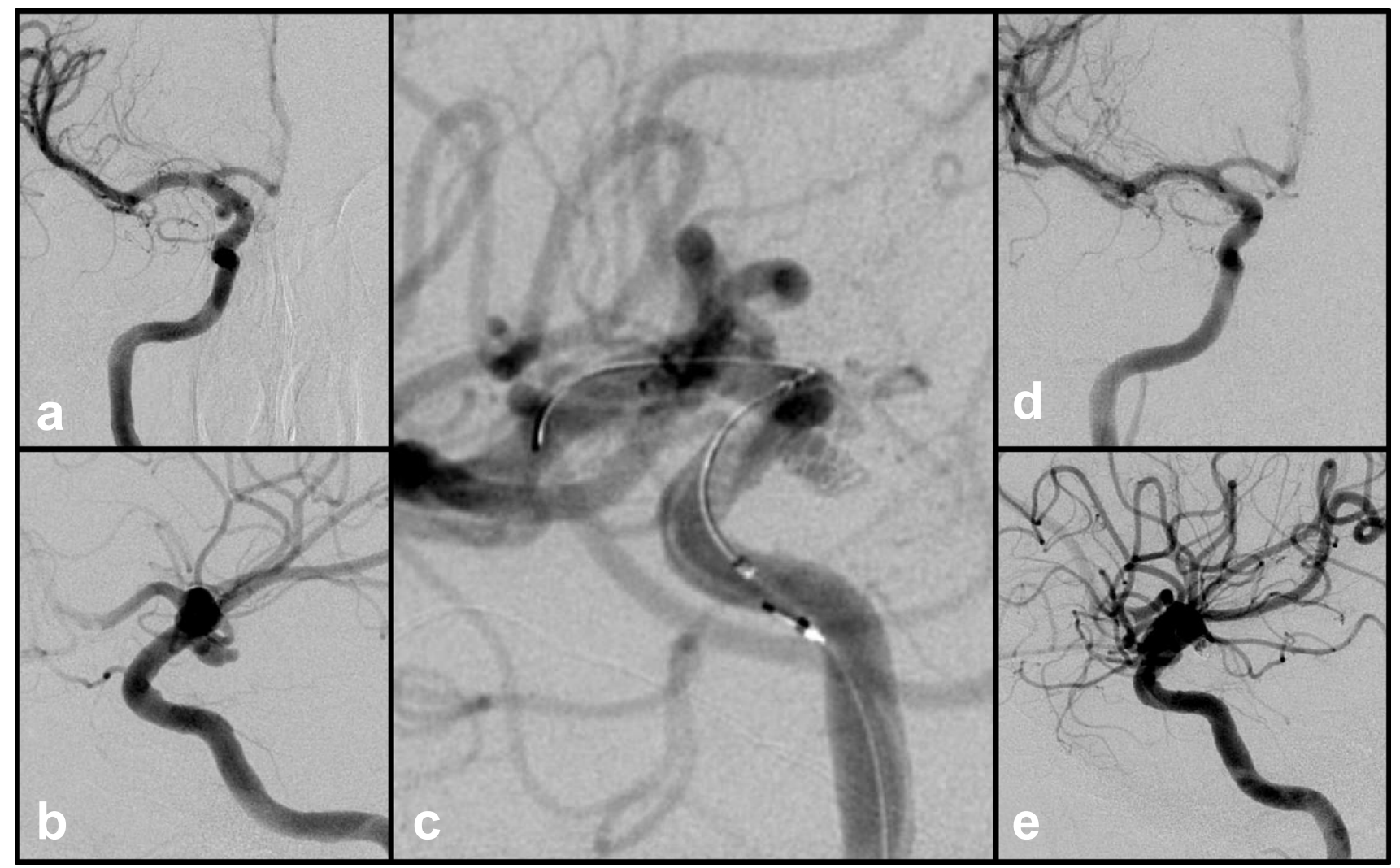

Fig. 2 Ruptured, wide-neck 4-mm right PCommA aneurysm in a poor surgical candidate. a AP and $\mathbf{b}$ lateral views. The initial framing coil would not stay in the aneurysm; thus, a balloon was inflated during placement of the initial framing coil allowing it to $\mathbf{c}$ remain

have demonstrated BAC to be safe and effective in treating IAs with an unfavorable dome-to-neck ratio $[17,129,130]$.

\section{Stent-assisted coiling}

The first coronary stent was implanted in a human in 1986, and by the twenty-first century, its use had increased to over $80 \%$ of all endovascular interventions in coronary arteries [42]. The first report of stent-assisted coiling (SAC) used for IAs was published by Higashida et al. only in 1997, for a ruptured fusiform IA of the basilar artery [41]. However, it was only in late 2002 that the first stent was actually designed for treatment of IAs. This was the Neuroform stent, which received a Humanitarian Device Exemption from the Food and Drug Administration (FDA). Stents in association with coils have been used to treat wide-neck IAs that cannot be treated by coils alone or with BAC. Stent cell design can be divided into open-cell and closed-cell types which have different physical properties. Closed-cell stents are characterized by small free cell areas between the struts, whereas open-cell stents have larger uncovered gaps. The primary objective of a stent within the aneurysm. $\mathbf{d}$ AP and e lateral views after subsequent coils were placed obliterating the dome. Dome remains obliterated at 2-year follow-up

application is to provide a scaffold to protect the parent vessel and permit coiling of wide-necked, giant, fusiform, and some other complex IAs, which are not amenable to coiling alone (Fig. 3). There are various configurations to achieve this (R-stent, L-stent, nonoverlapping-Y, virtual-Y, horizontal, kissing-Y which is a double stent placement in a parallel fashion, crossing-Y ( $\mathrm{R}$ to $\mathrm{L}$ ), and crossing$\mathrm{Y}$ ( $\mathrm{L}$ to $\mathrm{R}$ ) models). The principal limitation of simple coiling is the high IA recurrence, and hence, the adjunct use of stents for coil aims to reduce this recurrence [83]. More recently, novel endovascular devices have also been approved to specifically treat bifurcation IAs with wide necks. Among these devices, the pCONus1 and pCONus2 are stent-like self-expanding nitinol implant with four to six distal petals allowing coiling of the aneurysmal sac [108]. The PulseRider is another self-expanding nitinol implant with frame configuration that opens to conform to the vessel walls. These devices were specifically engineered to preserve luminal patency and hemodynamic flow through the parent vessel bifurcation, while minimizing exposed metal to expedite endothelialization [36, 91]. Exciting new devices include the pCANvas, pCONUSTM, 
Fig. 3 Unruptured 7-mm, widenecked ACommA aneurysm. a AP view demonstrating $\mathrm{Y}$ configuration stents with distal markers visible in each A2 segment (arrows) and proximal maker in the A1 (arrow) and $\mathbf{b}$ a $3 \mathrm{D}$ view of the neck. Post-coiling c AP and d lateral view demonstrating aneurysm obliteration without encroachment of the parent vessels

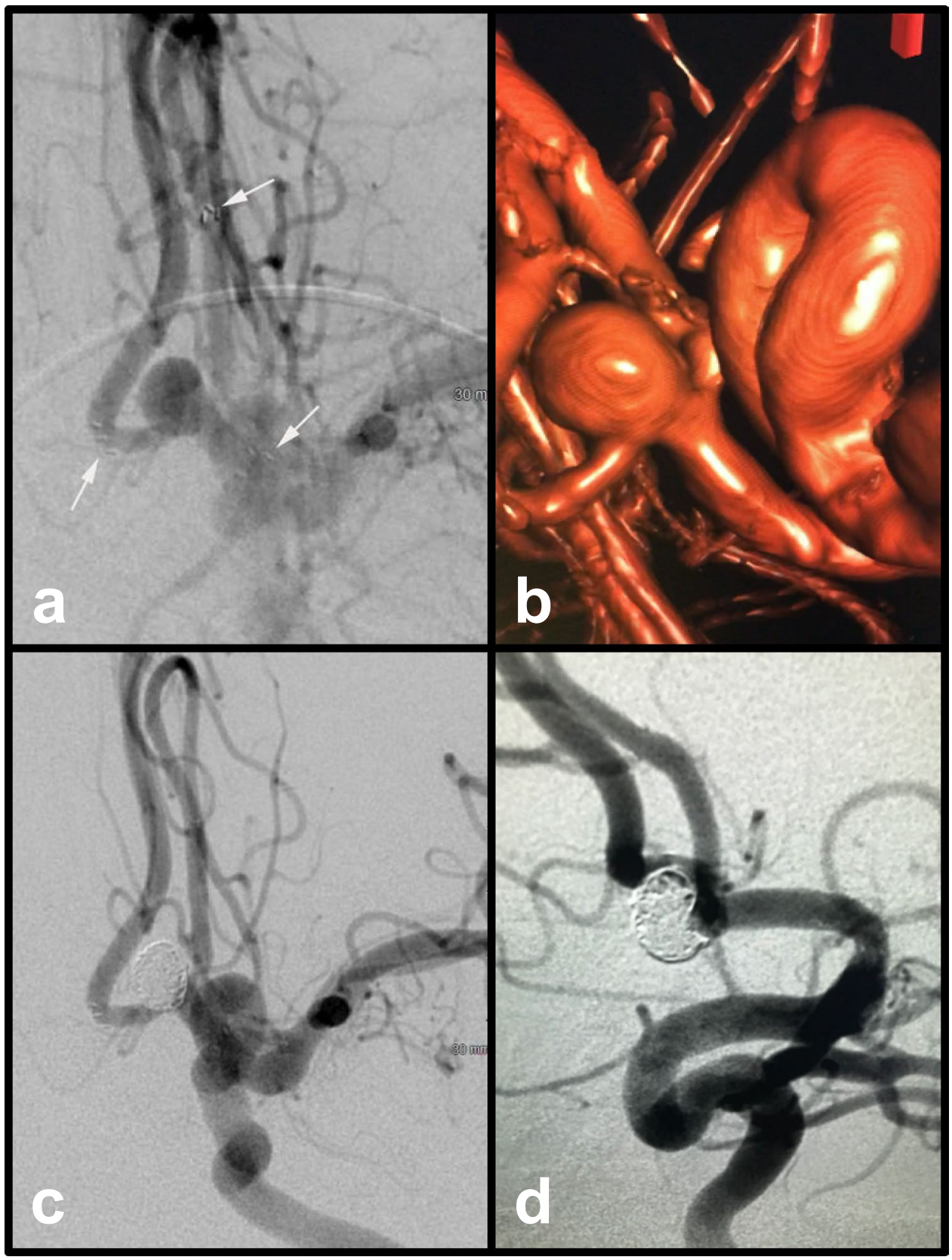

eClipsTM, and Comaneci. While larger institutional data are required, recent meta-analyses have demonstrated high rates of technical success and sufficiently low rates of morbidity and mortality with their use in wide-neck IAs [91, 108].

In a meta-analysis comparing the outcomes of 2698 SAC and 29,388 unassisted coiling patients [83], Phan et al. reported that both SAC and unassisted coiling were comparable in terms of similar immediate occlusion and complication rates. There were significantly lower rates of IA recurrence in SAC compared to coiling only ( $\mathrm{OR}=0.43 ; 95 \% \mathrm{CI}$ : $0.28-0.66$ ). However, progressive thrombosis was significantly more likely in SAC (29.9\%) compared to unassisted coiling (17.5\%) $(\mathrm{OR}=2.71$; 95\% CI: $1.95-3.75)$. $\mathrm{SAC}$ is also associated with a higher mortality rate $(\mathrm{OR}=2.16$; $95 \% \mathrm{CI}$ : 1.33-3.52).

However, while these devices provide another treatment option for endovascular repair, additional risks are associated with stent placement compared to coiling alone. Despite the generations of intracranial stents which have evolved over time, there are still a number of limitations with the current stent devices with rare complications, including stent migration, vessel trauma, thrombosis, and in-stent restenosis having been reported $[8,18,35,71]$.

With the use of stents or flow diverters, complication rates tend to be higher than with simple coiling or BAC due 
to metallic scaffold present in the parent vessel. The inherent thrombogenicity of these devices necessitates use of dual antiplatelet medication perioperatively and post-procedure to prevent thromboembolic events. The need for antiplatelet therapy limits the role of stent placement in patients with ruptured IAs as it increases the risk of the procedure as well as the need for adjunctive therapies such as external ventricular drains or CSF diversionary shunts $[58,136]$. Newer stents with modified surfaces to reduce their thrombogenicity can potentially be safely used with only a single antiplatelet agent. This application could potentially overcome some of the existing challenges when using flow diverters in the treatment of ruptured aneurysms [70].

\section{Double microcatheter technique}

The double microcatheter technique is an alternative to treat IAs with complex configurations, not amenable to simple coiling, such as a wide neck or the presence of vital vessels branching from the fundus $[6,52,104]$. This technique involves creating a stable coil frame using two coils to brace each other [135]. Prior to coiling, two microcatheters are placed within the proximal and distal aspects of the IA dome. The first coil is positioned proximally to form a supporting frame, while the other coils are deployed through the distal microcatheter. The coil frame is kept in place until packing is satisfactorily completed [142].

Besides its use for IAs with unfavorable configurations, a recent study of 85 patients demonstrated efficacy of the double microcatheter technique in treating very small IAs of $\leq 3 \mathrm{~mm}$ [135]. This technique has also been shown to be safe and effective in the treatment of a case of elongated middle cerebral artery (MCA) bifurcation IA [54]. However, care should be taken to prevent shifting of coils when disengaging the distal microcatheter. Additionally, concerns have also been raised about decreased coil packing density and increased recurrence rate using this technique.

\section{Flow diverters}

With the advent of computational fluid dynamics and improvement in imaging modalities over the past few decades, more research has begun focusing on medical device design. Flow diverters are a new generation of neuroendovascular devices that consist of highly flexible tubular structures with mesh and are very similar to stents in terms of engineering design [139]. A major difference is that the mesh is less porous than in typical stents. Therefore, the major focus in manufacturing design for flow diverters has been shifted from solid mechanics to fluid mechanics (Fig. 4).

The primary goal of a flow diverter is to shunt flow away from the IA by placing a mesh structure, similar to a stent, on the IA neck along the parent artery. By decoupling blood flow between the parent artery and aneurysmal sac, a flow diverter can create blood stasis in the IA to allow for thrombus formation inside the IA. The IA gradually thromboses and regresses over time, while the device acts as a scaffold for endothelialization across the IA neck resulting in parent vessel remodeling and IA resolution. Flow diverters are intended to be used in anatomical situations where SAC becomes difficult, and hence are suitable for use in wide-necked, giant, or fusiform IAs. Symptomatic cavernous segment IAs are preferentially treated with this technique, and ophthalmic region IAs are increasingly being treated by flow diversion rather than open surgical approaches. Additionally, dysplastic or fusiform IAs in other locations not amenable to straightforward endovascular or open vascular treatment are increasingly being treated in this manner.

In a recent meta-analysis, Madaelil et al. reported the use of flow diverters for 126 distinct ruptured IA cases, including dissecting $(28 \%, 35 / 125)$, fusiform $(10 \%, 12 / 125)$, giant (3\%, $4 / 125)$, blister $(38 \%, 47 / 125)$, and saccular $(22 \%, 27 / 125)$ types [69]. IA rerupture occurred in 5\% of the IAs, with $67 \%$ of these reruptures occurring in IAs measuring $>2 \mathrm{~cm}$. With a median follow-up of 6 months, complete occlusion of the IA was achieved in $90 \%$ of patients on follow-up clinical imaging, and favorable clinical outcome was attained in $81 \%$ of patients. Another meta-analysis assessing the outcomes of early (within 2 days) versus delayed flow diversion for ruptured IAs showed no statistical difference in overall hemorrhagic complication and stroke rates [30].

As mentioned, flow diverters are typically deployed in situations where established techniques are not viable options. It is not surprising that, with increased technical demands, deployment of flow diverters also comes with increased technical complications. Yet a recent meta-analysis still established its effectiveness and low associated morbidity/ mortality risks, in the use of US commercially available flow diverters predominantly in unruptured small/medium ICA IAs. At 12 months, occlusion was achieved in 74.6\% (95\% CI 66.8 to $81.7 \%$ ) of cases with low rates of primary safety events, at $7.8 \%$ (95\% CI 4.8 to $11.4 \%$ ) [34]. These recent findings are reassuring that flow diverters remain a viable option.

Delayed IA rupture (DAR) has been reported to be a complication associated with IAs treated with flow-diverting stents [97]. The mechanism of DAR is still not entirely elucidated but is likely due to the higher porosity of early available devices, limiting the flow-diverting effect [25]. In vitro studies have suggested that stent porosity and local hydrodynamic conditions play an important role in uncoupling flow between the parent vessel and the aneurysmal sac [122]. Further improvements of currently available devices (PED) have created less porous devices-Surpass (Stryker), p64 (Phenox), FRED (flow redirection endoluminal device) obviate some of these earlier issues [94]. 
Fig. 4 a AP and b lateral pretreatment angiogram demonstrating a giant left cavernous segment ICA aneurysm. c AP and $\mathbf{d}$ lateral projections of the left ICA 6 months after flow diversion treatment demonstrating resolution of the aneurysm and remodeling of the parent vessel

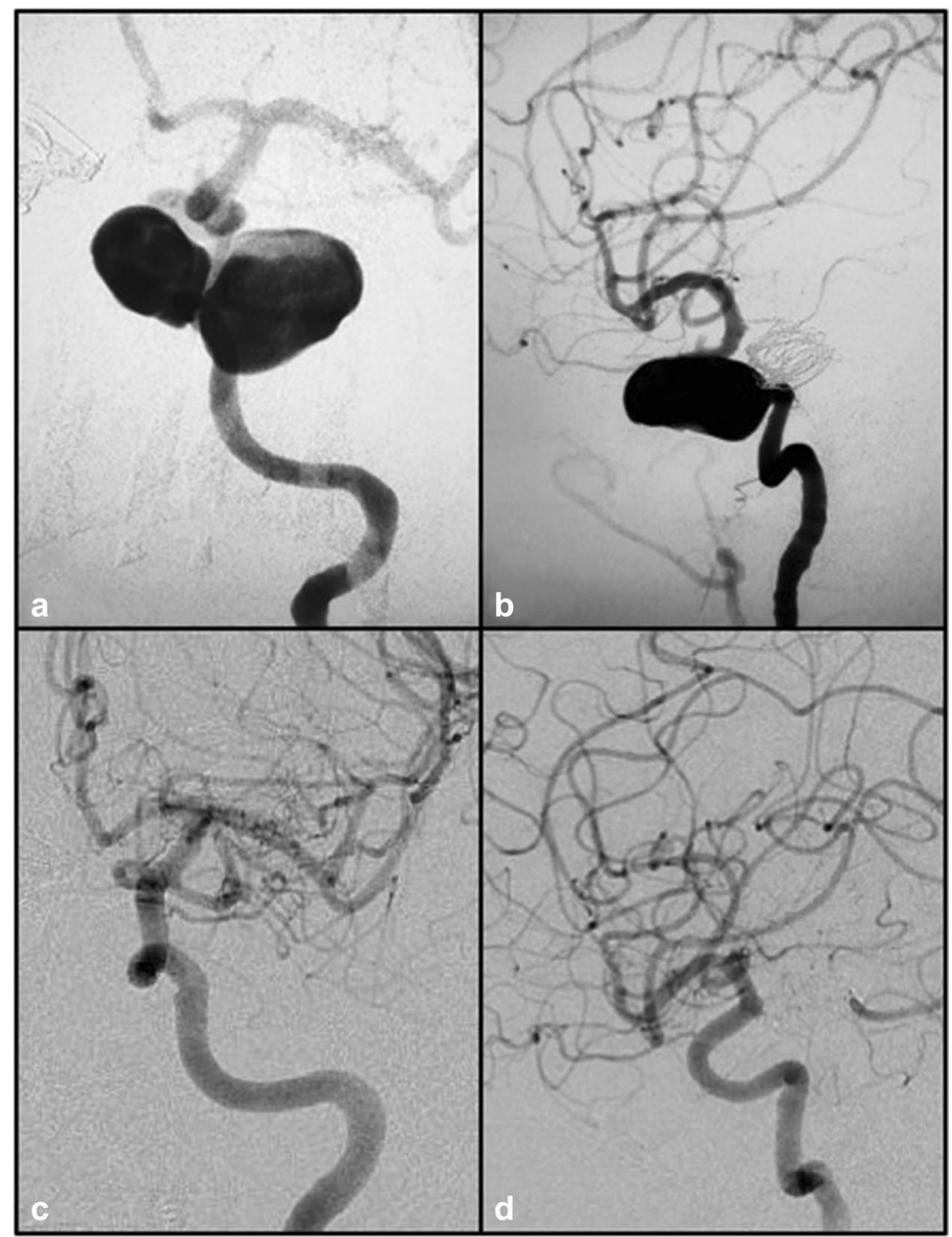

\section{Intrasaccular flow disruptors}

Intrasaccular flow disruption is a recently developed concept primarily proposed for the treatment of bifurcation IAs $[62,79,86]$. One such device commonly discussed is the Woven Endoluminal Bridge (WEB) (Fig. 5), which is deployed inside the aneurysmal sac to divert flow away from the dome leading to stagnation and thrombosis, and can be used for the treatment of saccular or widenecked bifurcation IAs, and even ruptured IAs [141]. There is little risk posed to surrounding perforators, and antiplatelet medication is not required after the procedure [84]. A multicenter European study demonstrated adequate occlusion of $89.7 \%$ at midterm follow-up of median 13 months, and good clinical outcome $(\mathrm{mRS}<2)$ of $93.3 \%$ at last follow-up [67]. The recent Woven EndoBridge Intrasaccular Therapy (WEB-IT) study demonstrated promising results, with only one $(0.7 \%)$ primary safety event in 148 patients which was a delayed ipsilateral parenchymal hemorrhage. No further primary safety events occurred beyond 30 days through 1 year. At the 1-year angiographic follow-up, $84.6 \%$ of patients had adequate occlusion with complete occlusion in $53.8 \%$ of subjects [5]. The safety and effectiveness of the WEB are also corroborated by other studies [87, 126].

An upcoming intrasaccular flow disruptor is the Luna Aneurysm Embolization System (AES), which is a selfexpanding ovoid braided implant that provides an attenuated 


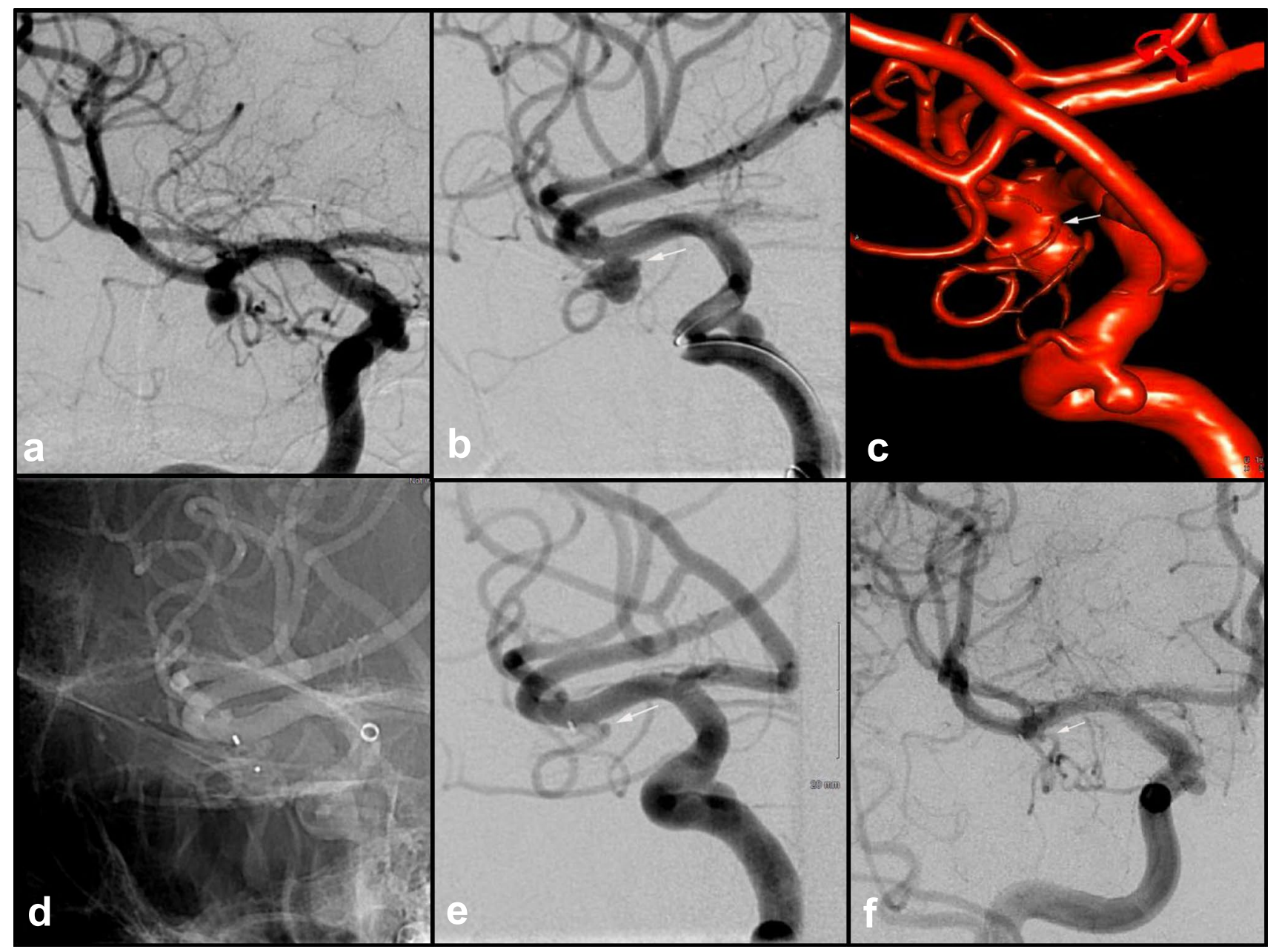

Fig. 5 Pre-treatment a AP, b lateral, and c 3D images of a right anterior temporal artery. MCA aneurysm with the anterior temporal artery originating from the neck (arrow). Immediate post-WEB device deployment $\mathbf{d}$ unsubtracted image showing the device and $\mathbf{e}$

mesh of metal across the IA neck when placed into the IA cavity. In a preliminary study, the Luna AES achieved high rates of complete angiographic occlusion in 12 rabbit IA models [53]. A more recent prospective multicenter study of 64 bifurcation and sidewall IAs demonstrated adequate occlusion of $79.2 \%$, with a morbidity rate of $1.8 \%$ and mortality of $1.6 \%$ at 36 months [88]. Further evidence is anticipated to evaluate the efficacy and safety of this device.

\section{Surgical techniques}

In the previous sections, we have discussed the use of BAC, SAC, and flow diversion to treat IAs with complex morphologies such as large, wide-necked, and fusiform IAs. Endovascular therapies have undoubtedly given multidisciplinary treatment teams important new treatment options. However, there remain several limitations to these subtracted lateral and image demonstrating aneurysm obliteration with patency of the branching artery (arrow). Six-month follow-up $\mathbf{f}$ AP image showing continued occlusion with patent anterior temporal artery (arrow)

methods that need to be addressed. BAC has been reported to be associated with an increased risk of long-term coil compaction and recanalization due to limited filling of the IA volume [23]. Meanwhile, SAC has been shown to have a greater periprocedural rate of hemorrhagic complications with the use of antiplatelet therapy [75]. Due to these limitations, treatment of more complex IAs such as bifurcation and sidewall IAs remains a challenge [2, 27, 100].

A summary of the current state of the microsurgical techniques, their indications, evolution, and current limitations, is presented in Table 2 .

\section{Microsurgical clipping}

Clipping of IAs is the most conventional and established method of IA treatment, with the first of such procedures dating back to 1937 [66]. It was not until 1975, when Yasargil and Fox introduced the microscope in the neurosurgeon's arsenal, 


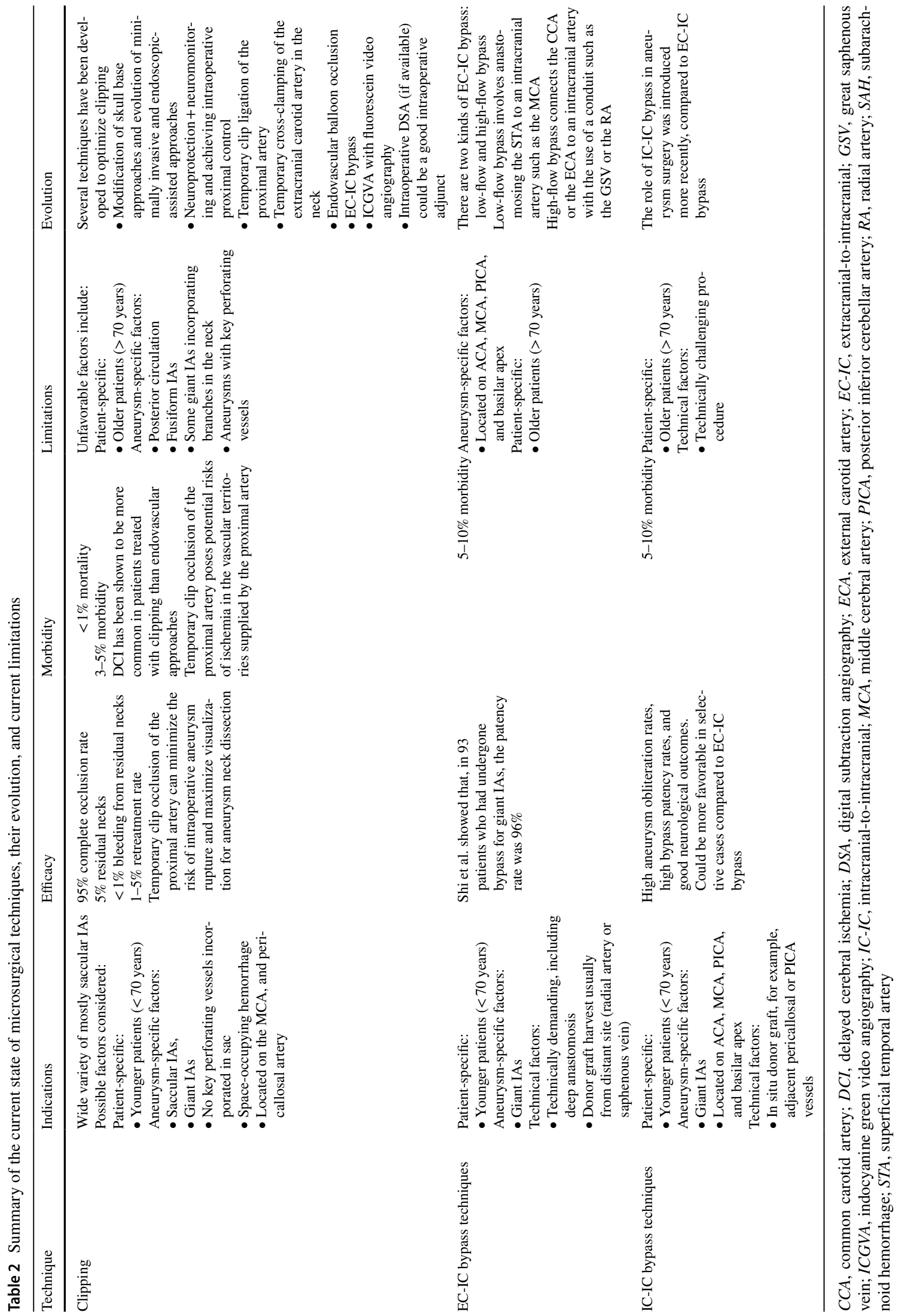


which afforded safe and effective exposure of the circle of Willis [134]. Principles of clipping involve gaining access to the IA via an open craniotomy, dissecting the IA away from surrounding parenchyma, optimizing visualization of the IA neck, and employing a metallic clip permanently to completely obliterate the neck without compromising the patency and integrity of the parent and perforating vessels (Fig. 6) [28].

Initial microsurgical techniques have improved with the modification of clip designs and microinstruments. There has been further evolution of access from modified skull base approaches to the so-called minimally invasive approaches to the use of endoscopy-assisted surgery [72]. This has been concomitantly associated with improvement in "neuroprotection" and novel techniques of achieving intraoperative proximal control for complex lesions. Some of these include the complementary role of endovascular techniques such as the use of intraluminal balloons for proximal control.

Several techniques have evolved as an adjunct of microsurgical clipping, to aid the surgeon in optimizing outcomes. These include temporary clip ligation of the proximal artery, temporary cross-clamping of the extracranial carotid artery in the neck, endovascular balloon occlusion with suction, and extracranial-to-intracranial bypass as well as cardiac standstill $[7,39,50]$. These will be further described below. Clipping is versatile and is a viable option for most types of IAs, including saccular IAs, giant IAs, and fusiform IAs without key perforating vessels [142]. Although reserved for fit and younger patients, microsurgical clipping is more suitable than coiling in patients with expanding hematoma or signs of raised intracranial pressure requiring urgent decompression $[1,76,81,116]$.

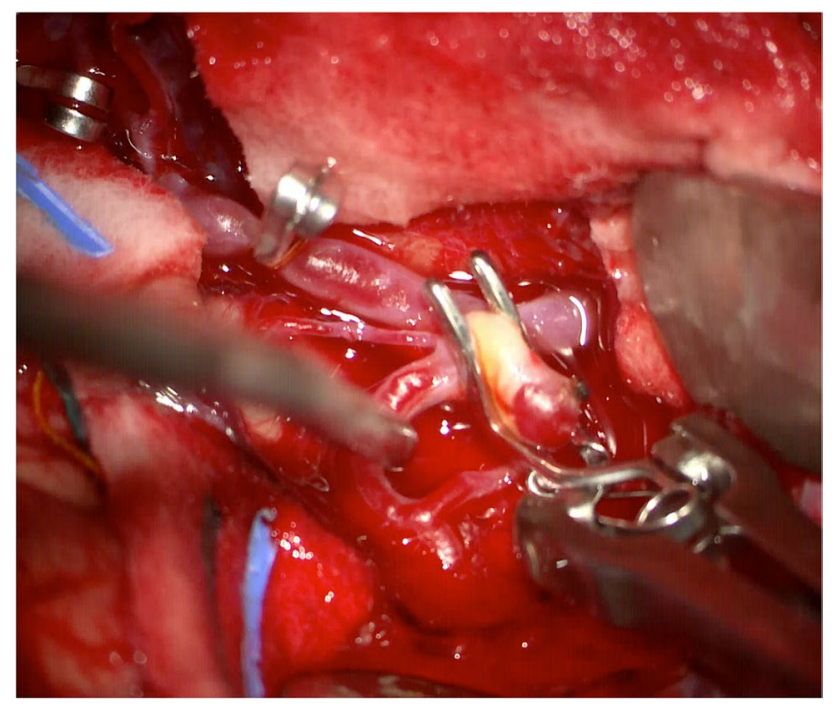

Fig. 6 Clipping of a partially calcified MCA bifurcation aneurysm is demonstrated here with temporary clipping of the M1 trunk to soften the aneurysm dome. In the upper left corner, a permanent clip is seen on a posterior communicating artery (PCommA) aneurysm (not shown) that was concomitantly clipped during the same operation
Temporary clip occlusion of the proximal artery is one of the most popular adjunct microsurgical clippings of IA, in order to minimize the risk of intraoperative IA rupture. By temporarily occluding the proximal vessel, blood supply to the IA is obliterated, causing the IA to soften and thereby maximizing visualization and IA neck dissection. However, this technique poses potential risks of ischemia in the vascular territories supplied by the proximal artery. To minimize the risk of ischemic complications, the occlusion time is typically kept to below 10-20 min [118]. In challenging cases where a single occlusion episode is insufficient, the use of multiple episodes of occlusion with 15-min reperfusions in between has been shown to be safe and effective [90]. With cerebral protection of hypothermia, anesthesia-induced burst suppression, combined with raising baseline blood pressure to encourage collateralization, longer temporary occlusion time is generally tolerated (in the event of microvascular anastomosis during cerebral bypass). However, the Intraoperative Hypothermia for Aneurysm Surgery Trial (IHAST) demonstrated that hypothermia aimed at neuroprotection during IA surgery did not improve the neurologic outcome after craniotomy among WFNS grade 1-3 patients with SAH [121]. Intraoperative rupture of an IA during microsurgery may have devastating consequences. Short-term cardiac arrest induced by intravenous adenosine with rapid cardiac pacing has been recently proposed as a feasible method to aid the surgeon, and has been demonstrated to be superior to temporary clipping during IA surgery $[9,43,68]$.

Advances in neuromonitoring are instrumental in providing safer surgery. More recently, the development of infrared indocyanine green video angiography (ICGVA) is increasingly finding its way as a quality control addition. ICGVA is a relatively new advancement in the field of cerebrovascular surgery with its first use in 2005 for intraoperative evaluation of vascular patency [92]. In a preliminary analysis of 114 patients, Raabe et al. demonstrated the effectiveness of ICGVA in providing real-time feedback on the patency of both the parenting and perforating vessels as well as information regarding the IA sac [92]. However, since then, several studies have raised concerns against the use of ICGVA as a single modality for intraoperative evaluation during IA clipping [55, 102, 131]. In one such study, Washington et al. demonstrated an ICGVA intraoperative angiography dis-concordance rate of $14.3 \%$, requiring post-intraoperative angiography adjustment of the IA clip [131]. These studies advocate the use of intraoperative digital subtraction angiography (DSA) as the gold standard for IA surgery, and suggest the use of fluorescein video angiography as a complementary technique to ICGVA in certain cases. A hybrid operating room might provide future solution for ontable DSA post IA clipping, though this is not current standard practice. Acknowledging the occurrence of technical mishaps during IA clipping [14], the use of ICG has allowed diminishing morbidity by modification of clip placement [117]. 


\section{Bypass techniques}

Bypass techniques used in cerebrovascular neurosurgery can be extracranial-to-intracranial (EC-IC) or intracranialto-intracranial (IC-IC). As these two types have clinically distinct indications and technical strategies, they are discussed separately.

EC-IC bypass, first described by Crowell and Yasargil, involves anastomosing an extracranial artery to a distal branch of the intracranial artery on which the IA is located [24]. The bypass allows safe ligation of the IA's parent artery and hence subsequent obliteration of the IA for complex cases in which clipping is technically challenging [112]. There are two kinds of EC-IC bypass: low-flow and highflow bypass. Low-flow bypass involves anastomosing the superficial temporal artery to an intracranial artery (STA-IC) such as the MCA, while the high-flow bypass connects the common carotid artery or the external carotid artery to an intracranial artery (CCA-IC or ECA-IC respectively) with the use of a conduit such as the great saphenous vein (GSV) or the radial artery (RA) [51, 115]. In general, low-flow bypass is the more popular choice, as a smaller and more gradual increase in inflow rate compared to high-flow bypass results in decreased risk of hyperperfusion injury [142]. However, in certain complex IA cases, high-flow bypass may be necessary as it encompasses the potential to supply a more substantial amount of blood flow to the brain [105]. Sekhar et al. demonstrated satisfactory outcomes of highflow bypass with an RA conduit in a series of 17 patients with IAs deemed inoperable with conventional microsurgical clipping (Fig. 7) [101].

Currently, the use of EC-IC bypass to treat IAs is reserved for giant or complex IAs. Giant IAs, which constitute $2-5 \%$ of all IAs $[65,114]$, often need to be surgically removed to alleviate symptoms due to mass effect. EC-IC bypass allows continuation of regional perfusion in areas distal to the IA after removal. More recent literature has reported increasing use of bypass techniques with improved patient outcomes [114]. In the earlier series, 30-day surgical mortality was high, but remained low at $1 \%$ or less in the more contemporary surgical series [16, $45,46,48,82,103,124]$. In one of the largest bypass series that included 93 patients with giant IAs (46\% involving ICA, $32 \%$ MCA, $18 \%$ posterior circulation), the bypass patency rate was $96 \%$, and long-term excellent or good outcome was observed in $94 \%$ of patients, at a mean

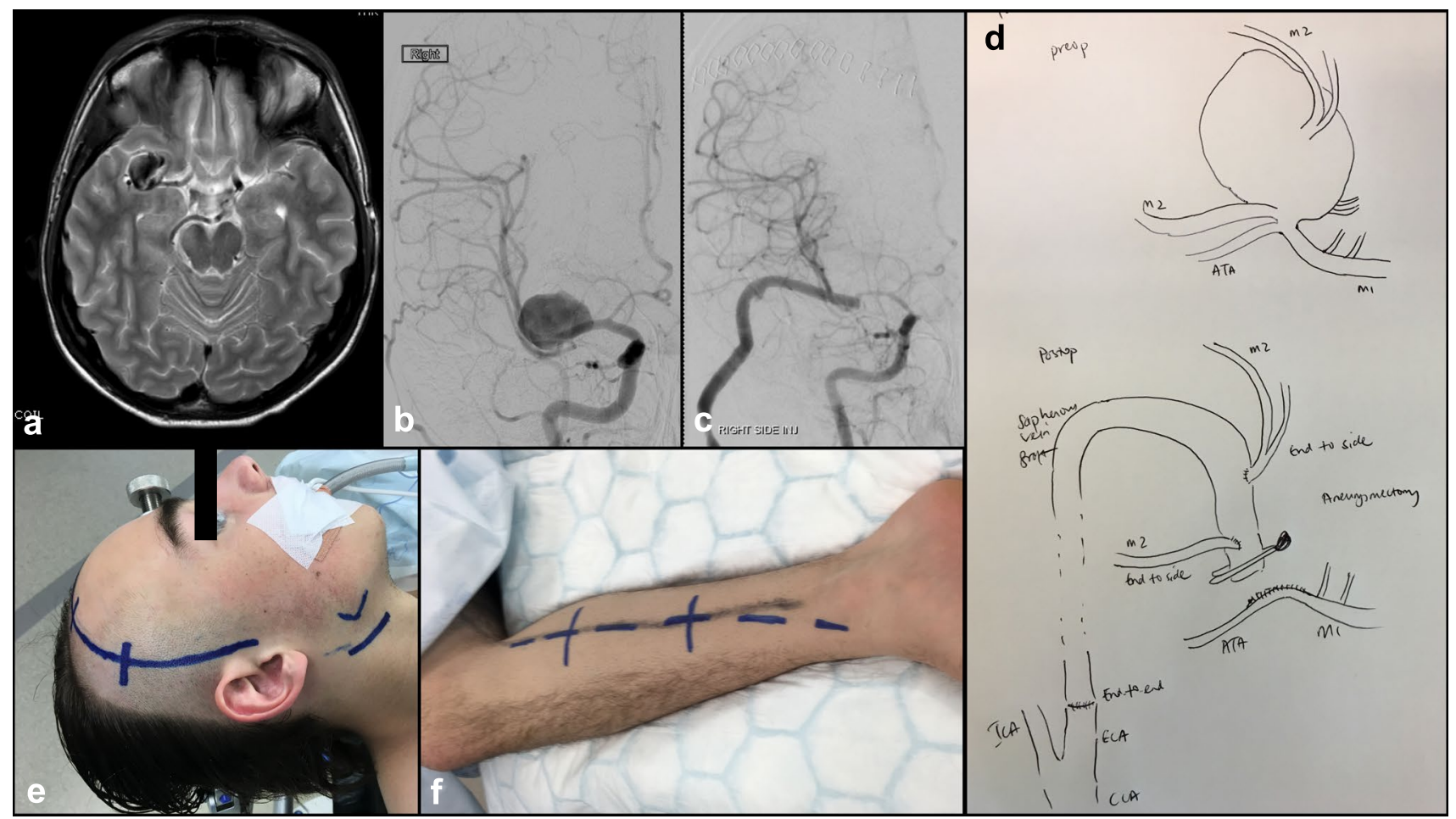

Fig. 7 An 18-year-old male presented with intermitted left-sided weakness. a MRI brain showed ischemic changes within the right MCA territory with wide-necked, complex MCA aneurysm. b Preoperative cerebral angiogram (right ICA injection) showed complex MCA aneurysm with MCA branches arising from the body of the aneurysm. $\mathbf{c}$ Right ECA-saphenous vein-MCA bypass (EC-IC bypass) was performed, with postoperative cerebral angiogram confirmed right MCA perfusion by high-flow bypass graft. $\mathbf{d}$ Schematic diagram to illustrate the complex aneurysm configuration, and bypass strategy, implanting the MCA branches into the saphenous vein graft. e, f Intraoperative view of the cranial incision, neck incision, and right saphenous vein harvest. He made good postoperative recovery, and resumed surfing 
follow-up of 3 years [103]. As such, EC-IC bypass is a viable consideration in cases where the IA is not amenable to microsurgical clipping or endovascular coiling.

The role of IC-IC bypass in IA surgery was introduced more recently (Figs. 8 and 9). IC-IC bypass involves revascularization and anastomosis of distal efferent branches with donor arteries that are completely in situ. Grafts such as the GSV or the RA may be used when a tension-free anastomosis is not possible, such as in the event that the donor and recipient vessels do not lie in close proximity [59]. While IC-IC bypass is a more technically challenging procedure, it is associated with higher IA obliteration rates, and higher bypass patency rates compared to EC-IC bypass according to some authors [99].

\section{Hybrid techniques: combination of both microsurgery and endovascular therapies}

Microsurgery and endovascular therapies are often viewed as competing treatments, but it is important to recognize their individual limitations. The ways in which endovascular techniques can be integrated into neurosurgical management, and vice versa, to enhance therapy have been underappreciated. As a result, controversy continues regarding the optimal management of IAs. A complex IA sometimes cannot be completely resolved with a single approach and its successful treatment requires a combination of microsurgical and endovascular techniques. Either technique could be a planned adjunct to the other or may be employed due to the primary failure of the other therapy. In this section, we will discuss how these two techniques could complement each other (Fig. 10).

\section{Microsurgical treatment post-endovascular therapy}

In the setting of a ruptured IA, microsurgery can be challenging due to complications such as hydrocephalus, brain edema, altered cerebral hemodynamics, and rarely even a subdural hematoma necessitating immediate hematoma evacuation with insertion of external ventricular drain [119, 138]. In such cases, microsurgical clipping may be used as a more definitive therapy after initial coil embolization which is better tolerated in the acute setting. As sometimes

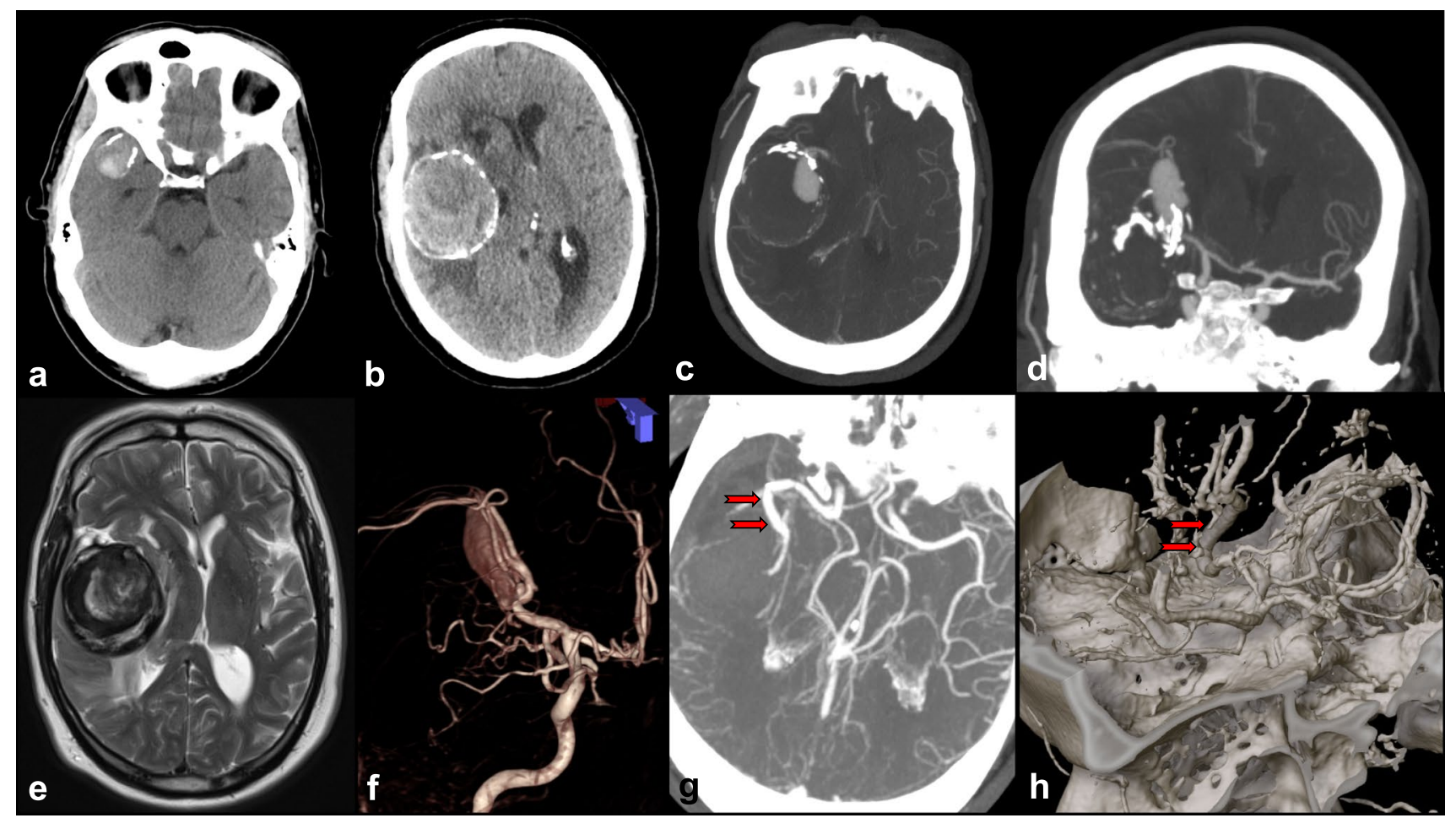

Fig. 8 A 65-year-old man, hypertensive, smoker, and with previous TIAs, was diagnosed with a large right MCA aneurysm 13 years prior that was managed conservatively (a). He presented with progressive left hemiparesis, impaired conscious level. b CT head showed a heavily calcified giant right MCA aneurysm with surrounding edema. c, d CT angiogram (axial and coronal views) showed patent aneurysm remnant, heavy calcification at the aneurysm neck, and thick layers of intraaneurysmal thrombus. e MRI brain, T2-weighted, axial view showed onion-ring appearance of multilayered intraaneurysmal thrombus. f $3 \mathrm{D}$ reconstructed angiogram showed single MCA branch arising from the aneurysm neck. g He underwent aneurysmectomy with in situ MCA end-to-end anastomosis using interposition saphenous vein graft (IC-IC bypass) and made good recovery. At 6 months follow-up, he was independently mobile, with resolution of hemiparesis. $\mathbf{g}, \mathbf{h}$ CT angiogram confirmed patent in situ bypass graft (red arrows) 


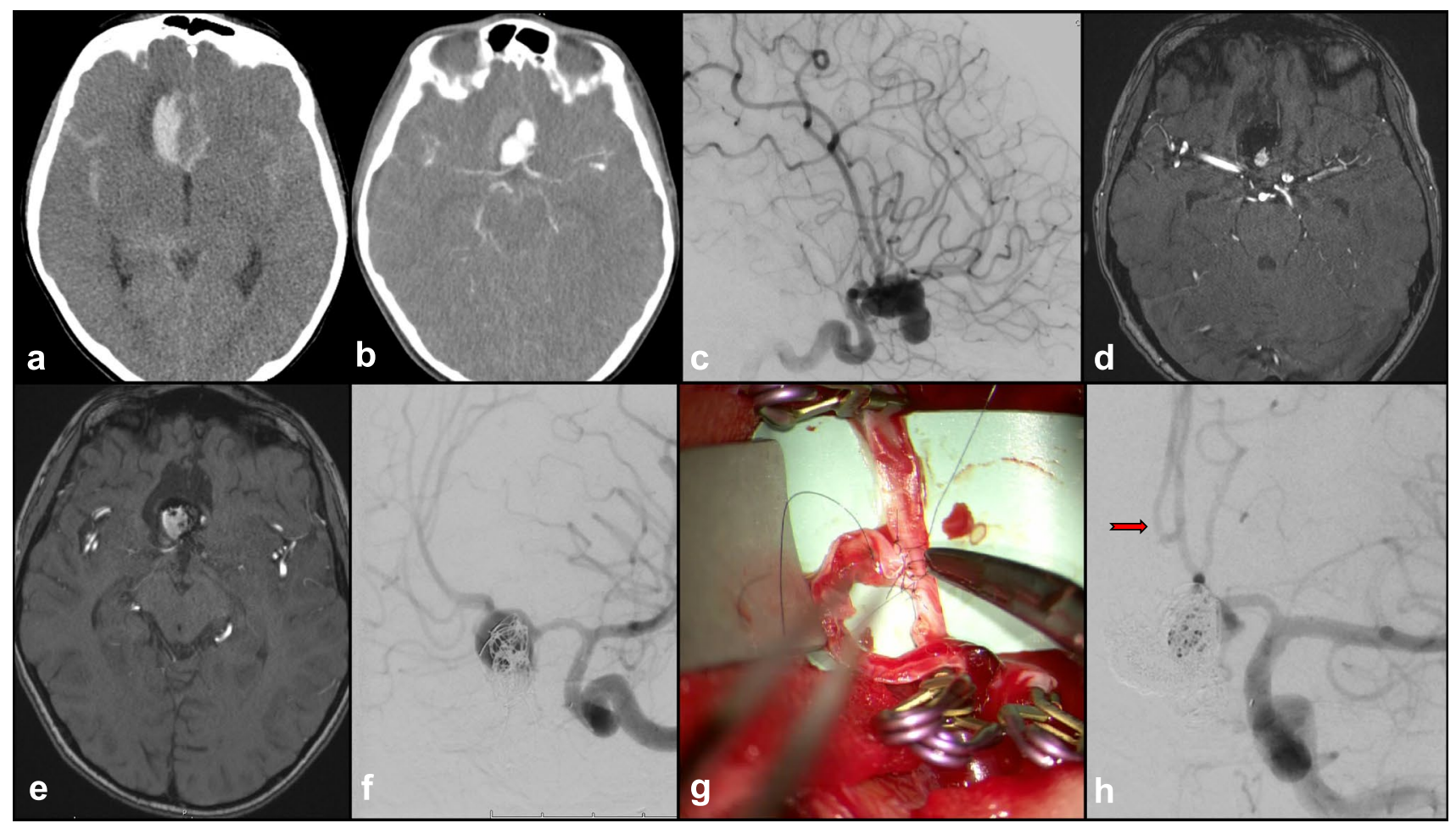

Fig. 9 A 10-year-old patient presented with coma producing aneurysmal SAH. Preintubation, his best motor score was flexing. a CT head showed diffused SAH, with associated frontal hematoma. b CT angiogram confirmed an underlying complex multilobulated anterior communicating artery (ACommA) aneurysm. c Cerebral angiogram (R ICA injection) showed the multilobulated ACommA, and right A2 arising from the neck of the aneurysm. He underwent coil occlusion of the ruptured ACommA, securing the ruptured fundal component. d MR angiogram, small neck remnant of coiled aneurysm was evident to protect the right A2 branch. After a period of ICU stay and rehabilitation, he made good recovery. e MR angiogram at 6 months follow-up showed significant aneurysm recurrence. $\mathbf{f}$ Cerebral angiogram (left ICA) injection showed ACommA aneurysm enlargement. After multidisciplinary discussion, we proceeded to perform right pericallosal to left pericallosal in situ (IC-IC) bypass, prior to further coil occlusion of the aneurysm, sacrificing the right A2. g Intraoperative view of pericallosal-pericallosal in situ bypass (IC-IC), end to side technique using interrupted $9 / 0$ suture. h Angiogram after further coil occlusion of the recurrent ACommA aneurysm, and left A2 supplying both pericallosal branches (red arrow) ruptured IAs have unfavorable anatomy for cure with coiling, a common strategy in this setting is IA dome coiling for rupture protection immediately post-rupture with a planned future definitive curative procedure in a delayed manner. In this setting, adjunct microsurgical clipping may be used as a the definitive therapy if the patient recovers and has a known neck residual or there is IA regrowth on a delayed basis [128].

In the setting of severe vasospasm in $\mathrm{SAH}$, it would be wise to avoid initial definitive microsurgical manipulation of vessels. Partial coiling followed by staged definitive clipping could be a better strategy to employ but access is often an issue if there is severe vasospasm [12].

Of course, this strategy is not amenable to all types of IAs. Partially coiled IAs can be structurally difficult to manipulate. If coils extend to the IA neck, they can hold the IA walls apart and prevent closure of the neck. This can potentially transform the soft neck into a wedge. If an adjunct clip were to be employed, it could lose traction and be splayed, resulting in it sliding down the neck and occluding parent and branch vessels. Thrombus formation within coils may also solidify the IA. In some cases, the IA dome may need to be opened with some coil and thrombus content removal before clipping can be safely performed [128].

Performing a preoperative endovascular balloon test occlusion (BTO) of a proximal parent vessel prior to microsurgical vessel sacrifice can be extremely beneficial in cases of complex IAs. BTO is usually only reserved for large vessels such as the ICA and vertebral artery, as it has a high risk or complication in smaller vessels. The apprehension of the risk of therapeutic artery sacrifice has urged preprocedural risk evaluations. Temporary BTO is a provocative test that transiently arrests blood supply to the areas that would be permanently affected following a vessel sacrifice. BTO is now widely used in patients with complex IAs as it helps determine which patients may require a bypass and whether a high- or low-flow bypass may be needed. A systematic review conducted by Linskey et al. showed that applying 


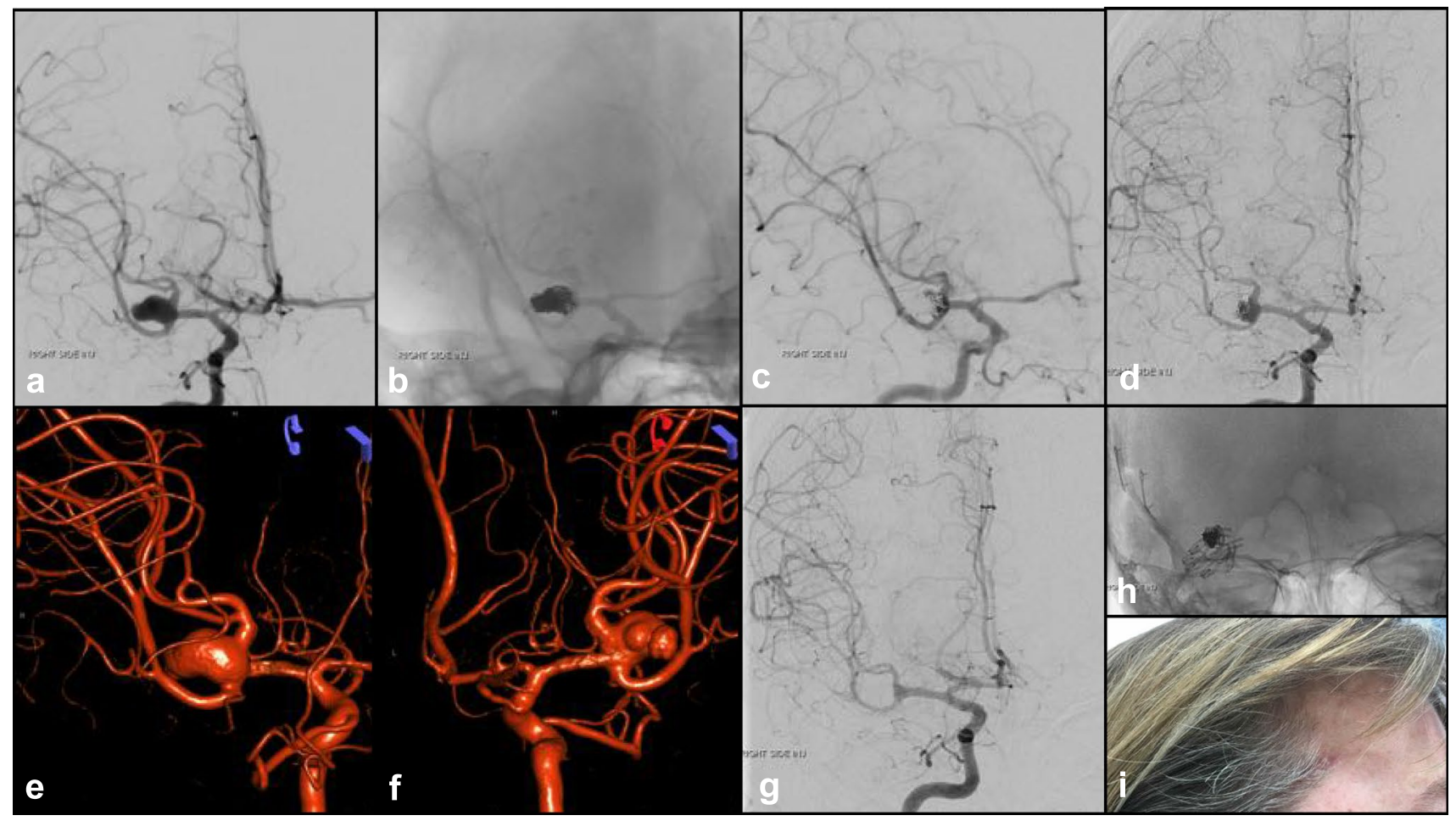

Fig. 10 A 50-year-old patient with poor-grade SAH, treated by hybrid approach. a Cerebral angiogram (right ICA injection) confirmed a complex right MCA aneurysm. b, c Post-coiling angiogram showed satisfactory aneurysm occlusion, with protection of the fundal bleeding point. d Six months follow-up angiogram showed aneurysm neck recurrence/coil compaction. e, f 3-Dimensional reconstructed

BTO prior to ICA occlusion considerably reduces the incidence of postoperative stroke and mortality from 26 and 12 to $13 \%$ and $3 \%$, respectively [64]. In certain cases, BTO should be avoided as it might propagate dissection or thromboembolic complications.

\section{Endovascular therapy post-microsurgical treatment}

A number of IAs are treated with clipping given their widebased morphology which makes stable coil constructs difficult. Microsurgical treatment is invasive and is frequently avoided in high-risk and high WFNS grade aneurysmal SAH patients, owing to prolonged brain retraction, difficulty of vessel dissection, and the need for longer anesthesia. Compared to endovascular coiling, more brain manipulation and hemodynamic changes are implicated in microsurgical clipping. Postoperative cerebral blood flow and cerebral metabolic rate for oxygen may be decreased in the postoperative period secondary to brain retraction [137].

Microsurgical clipping allows protection of a large part of the IA, but in complex IAs, due to a limited surgical corridor, a segment of the IA neck may be hidden from view, angiogram (AP, PA views) showed the complex wide-necked MCA aneurysm configuration with multiple daughter sacs. g Post-clipping angiogram confirmed complete right MCA aneurysm obliteration, using $\mathbf{h}$ clip reconstruction technique preserving MCA branches (i), via mini-pterional approach

resulting in residual IA filling after the IA neck is clipped [21]. In such settings, a partial microsurgical clip reconstruction of the IA can help create a narrow neck, which makes subsequent coil embolization of the residual IA possible. This scenario is encountered in carotid cave and paraclinoid IAs where part of the IA extends beyond the dural ring. This unique anatomy prevents placement of a microsurgical clip without dissection of the cavernous sinus, which can have significant morbidity. Reconstruction of a narrow neck permits easy coiling of the IA. While neck reconstruction to favor coiling can help, it can alter flow dynamics with a higher flow jet toward the IA dome, increasing likelihood of rupture. Therefore, second stage coiling should be completed soon after clip reconstruction. Wrapping with muslin may afford protection from rupture until subsequent coiling [20].

A common scenario for the use of coil embolization after clipping is with IA recurrences. Patients with an enlarging IA residual can be treated with coiling, possibly with balloon and stent assistance. This prevents the need for reoperation for a previously clipped IA and avoids issues with scarring and high surgical risk. 


\section{To coil or to clip? What is the best available evidence?}

The emergence of endovascular therapy has inevitably reduced cases of open surgery [73]. Endovascular treatment is preferred for certain posterior circulation IAs; however, surgery is a durable and effective option for certain IAs, particularly MCA IAs [140]. Although traditionally deemed as competitors, both microsurgical and endovascular approaches should complement each other.

The ISAT and Barrow Ruptured Aneurysm Trial (BRAT) were the only large randomized controlled trial (RCT) that compared clipping with coiling in patients with ruptured IAs, suitable for either treatment $[73,110]$. However, results of the ISAT have continued to spark debates and controversy, mainly because of its selection bias. The vast majority of patients had a favorable grade at the time of enrolment, $95 \%$ of the IAs were in the anterior cerebral circulation, and $90 \%$ were $<10 \mathrm{~mm}$, which made these results difficult for clinicians to generalize to treatments of specific IAs. As explained, there is no blanket technique to treat all kinds of IAs, due to variations in morphology, anatomy, location, and rupture status. The decision made would have to be guided by best available evidence, operator experience, and finally individualized joint decision between the patient and multidisciplinary teams composed of neurosurgeons, neurologists, critical care physicians, and interventional neuroradiologists. Since then, more RCTs, as well as observational studies, have been published, some of which have results that differ from that of the ISAT. Ten-year analysis from the BRAT demonstrated that, after 1 year, clinical outcomes for patients with anterior circulation IAs were comparable in both groups; clipping had several advantages over endovascular treatment, including greater rates of complete IA obliteration and reduced rates of retreatment [110]. Hence, more randomized and long-term data are needed.

The Cochrane review by Lindgren et al. on this topic only included four RCTs and the results principally favored those of the ISAT, due to its dominance in patient numbers [63]. There have been other published meta-analyses comparing the two treatment modalities, which include data from observational studies, specifically in the treatment of patients with unruptured MCA IAs [3], and patients with oculomotor nerve palsies induced by posterior communicating artery IAs [143]. We summarize in Table 3 the systematic reviews and meta-analysis which are most up-to-date or comprising largest dataset, comparing outcomes (efficacy, complications rates, morbidity, mortality, and economic status) of microsurgical and endovascular approaches for IAs by type, location, and rupture status.

When making a decision of which treatment, the following factors are crucial to consider: (1) age, past medical history, and comorbidities help to determine the patient's ability to tolerate a specific treatment. A young patient with a ruptured IA may be a good candidate for open surgery with better prospects of a long-term durable result, with lower rates of rebleeding [60]. In contrast, in an elderly patient with comorbidities with a ruptured IA and a diffusely swollen and friable brain, coil embolization may be favored over surgery. (2) IA characteristics such as location (suitability for surgical access), morphology, and size. Basilar tip IAs are notorious to treat with open surgery and are associated with higher surgical morbidity compared to IAs of other locations, so endovascular treatment is usually the preferred choice of treatment, although many indications still exist for the use of microsurgery [123]. MCA IAs typically have wide necks with important perforating branches originating from its dome or base. In such cases, endovascular coiling may not be performed safely without compromising flow. In such a scenario, surgery offers the option of clip reconstruction of the IA while preserving important perforators and bifurcation vessels. A ruptured IA with intraparenchymal hematoma causing significant mass effect is likely better suited for surgery. (3) Operator's experience and preferences. This includes the operator's bias toward a certain treatment because of experience and familiarity. (4) Finally, an equally important but often understated factor is the patient's preference. Patients may prefer the cosmetic benefit of the minimally invasive endovascular approach but should always be informed of the short- and long-term risks associated with it. (5) It is also noteworthy that, on a global level, the higher direct cost of endovascular treatment is by far a major determinant of treatment selection in low- and middle-income countries (LMICs) [32]. In LMICs, this is of even more concern given the lack of access to much of the world's population to surgical and, more specifically, neurosurgical, interventional, and anesthesiologic expertise [29, 80, 98].

\section{Evolution of intracranial aneurysm treatment techniques}

The treatment of IAs has undergone very significant paradigm shifts in the recent decades. The introduction of any new device is inevitably accompanied by evolution of the technique as clinical experience grows and case selection improves. This phenomenon will continue to prevail with further technological advancements. This conversely can lead to the paradox of choice. With a large armamentarium of IA treatment techniques, one of the challenges of the operator may be to face achieving mastery in the surgical techniques or devices of their trade while keeping pace with the explosive evolution of technology and techniques. In addition, using a range of techniques may reduce their expertise in each individual technique. Any new technique assessed must account for the 
Neurosurgical Review (2022) 45:1-25

17

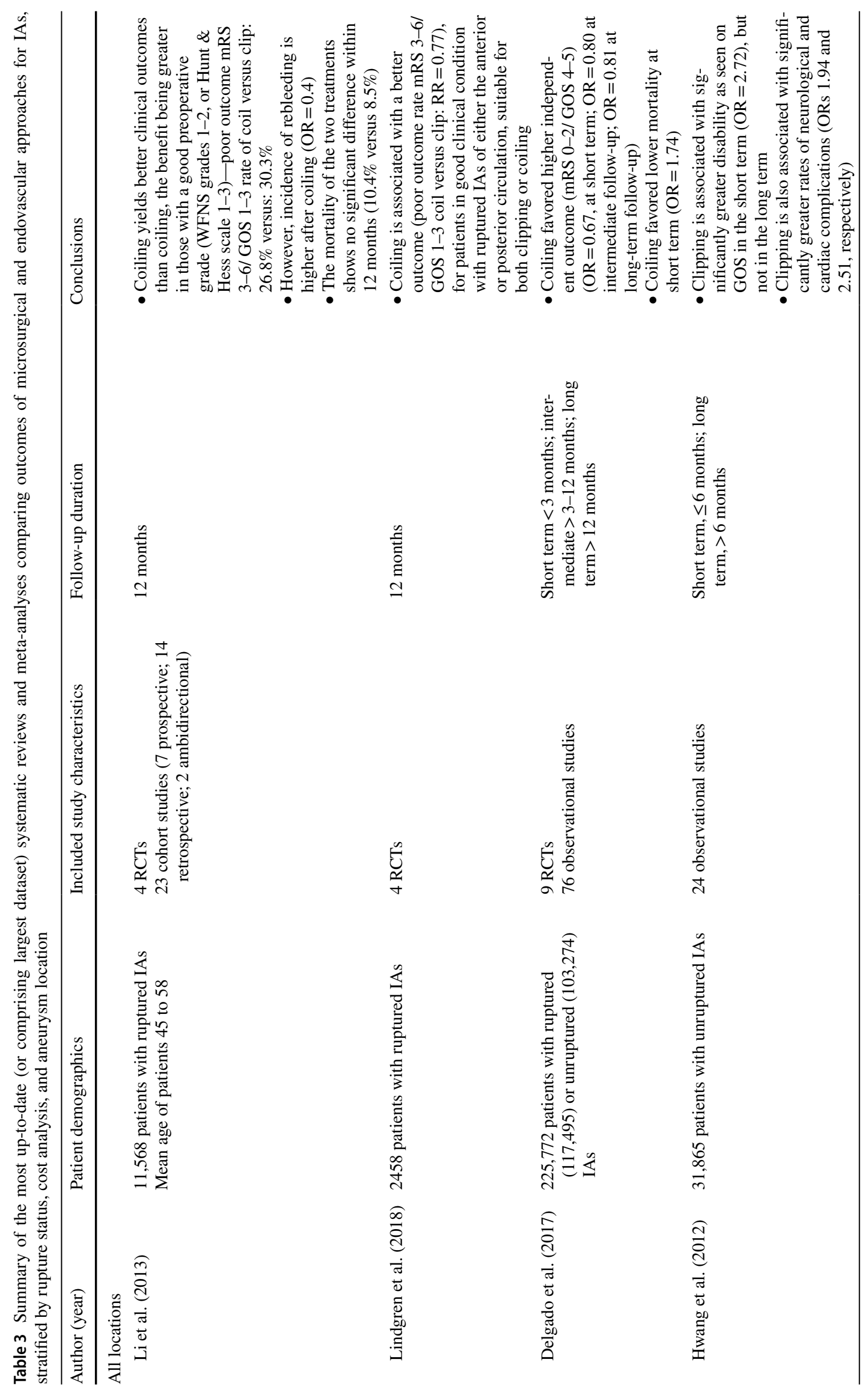

Springer 


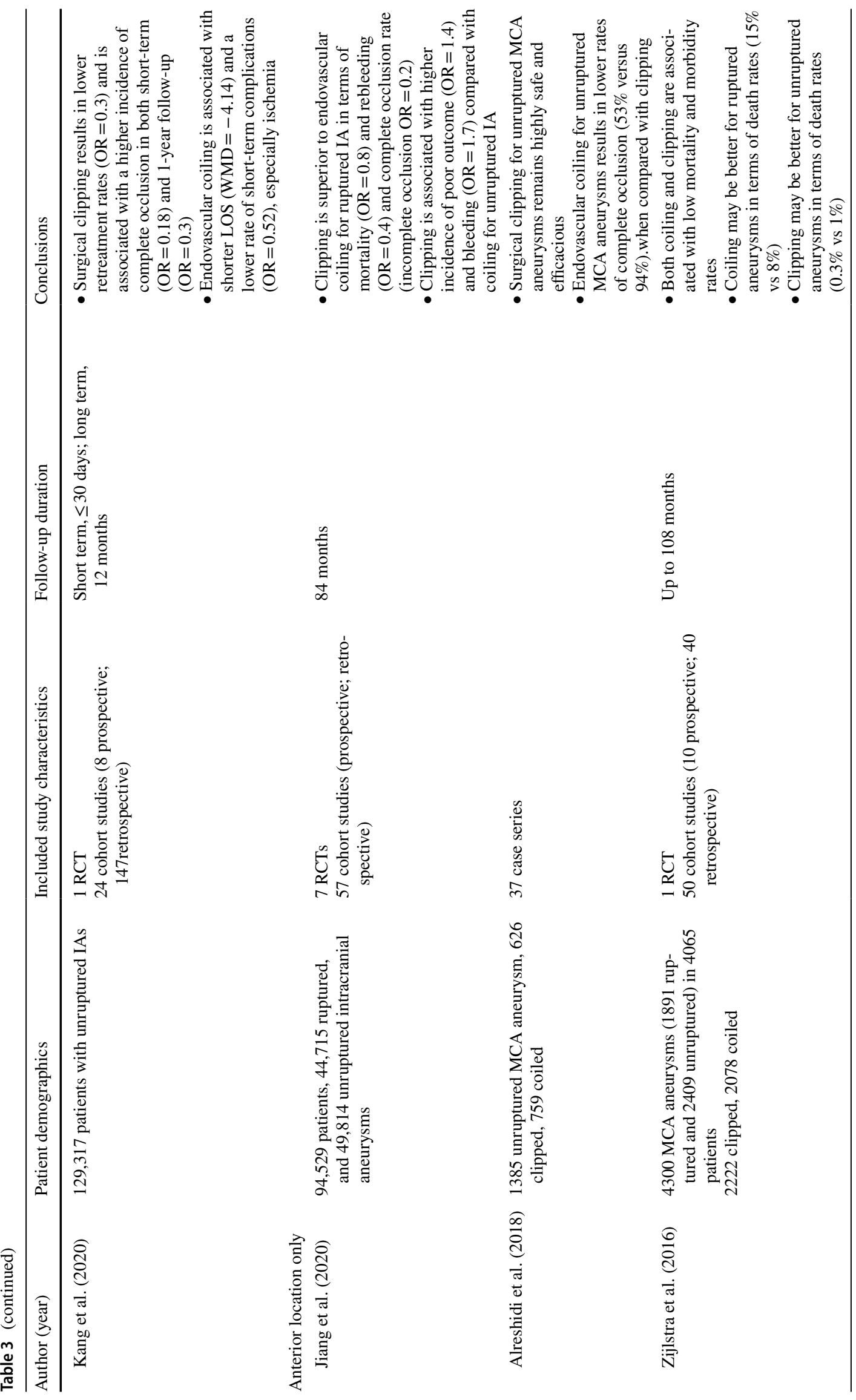




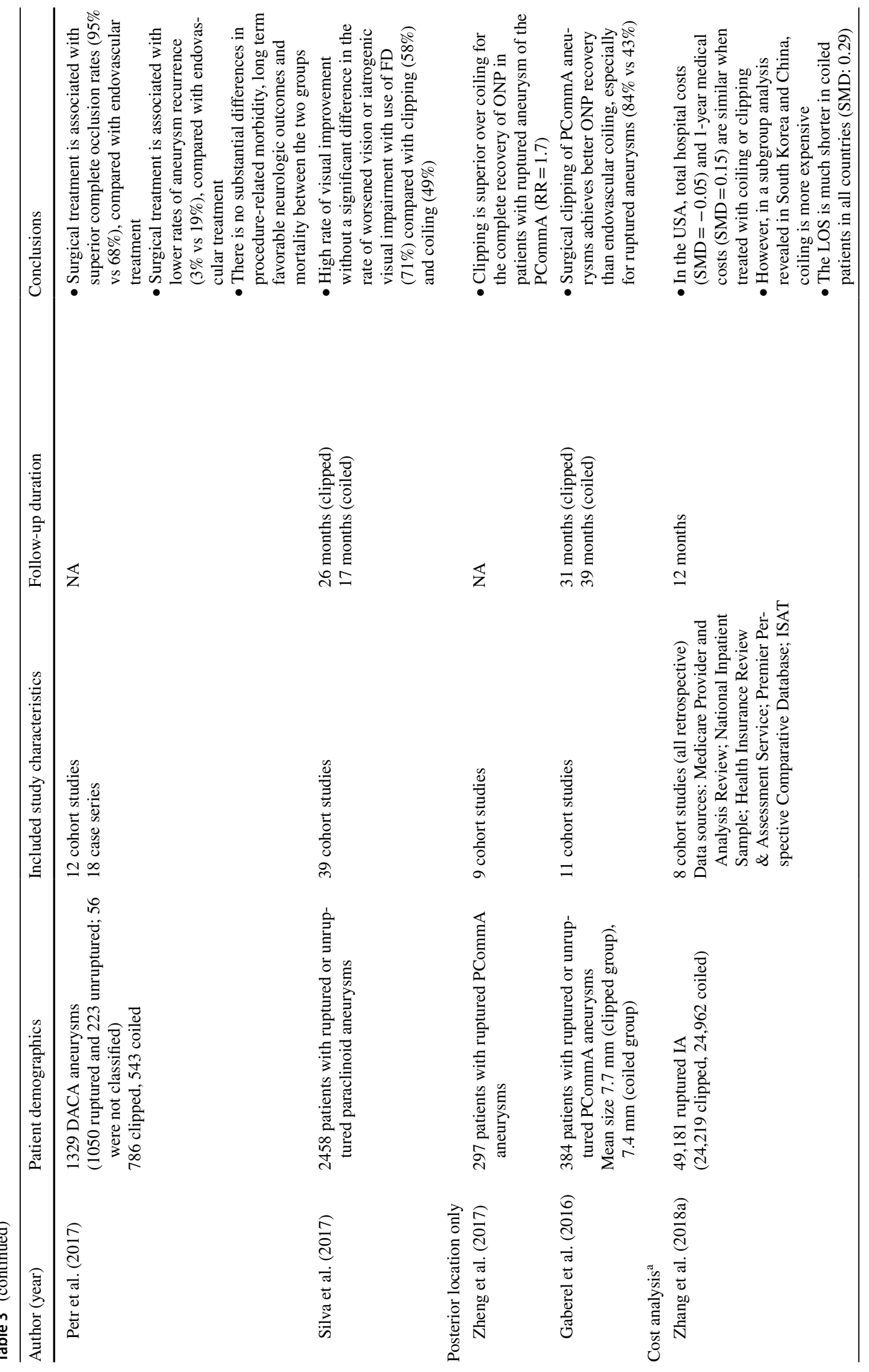


options that are available to the patient and the likely outcomes of those options. The technology should be generalized for use by most of the expert community, because, if it is too esoteric or technically demanding, it may not be commercially and clinically successful. Thus, the evaluation of new techniques should be carried out in multiple centers with a diversity of clinicians as this provides a more representative reflection of what can be expected when a device is made readily available. Future directions and innovation for IA treatment techniques will be based on the refinement of currently available technology and driven by what is identified as current limitations of established techniques. The ultimate aim of the evolution is to address current shortfalls and reduce complications and morbidity. For example, the advent of flow diverters has helped overcome prior limitations of SAC in the treatment of widenecked, giant, or fusiform IAs. Understanding whether the new devices and surgical techniques are at least equally safe and potentially more effective than currently available treatments and whether IAs of different locations and subtypes can be treated safely and completely remains an ongoing challenge in cerebrovascular neurosurgery. Finally, addressing the cost issue of emerging technologies is also of major importance to enable application in LMICs [29, 80, 98].

\section{Conclusion}

We summarized the available treatment options for IAs. The treatment should be approached in a multidisciplinary manner, taking into account the characteristics of the IA, patient's comorbidities, the patient's preferences, and the experience of the operator. The patient's condition at presentation plays an important role in the decision-making by experienced neurovascular surgeons and endovascular specialists. In certain complex IA cases, a single approach may be inadequate to completely treat it, and its successful treatment requires a combination of microsurgical and endovascular techniques. Ultimately, it is intended that this review will allow the reader to apply the best matched evidence to decide the best approach towards a particular lesion.

Author contribution All authors listed have made substantial, direct, and intellectual contribution to the work and approved it for publications.

Keng Siang Lee: conceptualization, investigation, writing—original draft, writing — review and editing, visualization, funding acquisition.

John J. Y. Zhang: investigation, writing — original draft, writingreview and editing, visualization.

Vincent Nguyen: writing-review and editing.

Julian Han: writing-review and editing, supervision.

Jeremiah N. Johnson: writing—review and editing, supervision.

Ramez Kirollos: writing—review and editing, supervision.

Mario Teo: writing—review and editing, supervision.

Funding Open Access funding provided by the University of Bristol. 
Data availability Not applicable.

Code availability Not applicable.

\section{Declarations}

Ethics approval Not applicable.

Consent to participate Our participants gave written informed consent for publication of their photographs.

Consent for publication Our participants gave written informed consent for publication of their photographs.

Conflict of interest The authors declare no competing interests.

Open Access This article is licensed under a Creative Commons Attribution 4.0 International License, which permits use, sharing, adaptation, distribution and reproduction in any medium or format, as long as you give appropriate credit to the original author(s) and the source, provide a link to the Creative Commons licence, and indicate if changes were made. The images or other third party material in this article are included in the article's Creative Commons licence, unless indicated otherwise in a credit line to the material. If material is not included in the article's Creative Commons licence and your intended use is not permitted by statutory regulation or exceeds the permitted use, you will need to obtain permission directly from the copyright holder. To view a copy of this licence, visit http://creativecommons.org/licenses/by/4.0/.

\section{References}

1. Aboukais R, Zairi F, Bourgeois P, Boustia F, Leclerc X, Lejeune JP (2015) Pericallosal aneurysm: a difficult challenge for microsurgery and endovascular treatment. Neurochirurgie 61:244-249

2. Albuquerque FC, Gonzalez LF, Hu YC, Newman CB, McDougall CG (2011) Transcirculation endovascular treatment of complex cerebral aneurysms: technical considerations and preliminary results. Neurosurgery 68:820-829 (discussion 829-830)

3. Alreshidi M, Cote DJ, Dasenbrock HH, Acosta M, Can A, Doucette J, Simjian T, Hulou MM, Wheeler LA, Huang K, Zaidi HA, Du R, Aziz-Sultan MA, Mekary RA, Smith TR (2018) Coiling versus microsurgical clipping in the treatment of unruptured middle cerebral artery aneurysms: a meta-analysis. Neurosurgery 83:879-889

4. AngioCalc, AngioCalc Cerebral and Peripheral Aneurysm Calculator.

5. Arthur AS, Molyneux A, Coon AL, Saatci I, Szikora I, Baltacioglu F, Sultan A, Hoit D, Delgado Almandoz JE, Elijovich L, Cekirge S, Byrne JV, Fiorella D, W.-I.S. investigators (2019) The safety and effectiveness of the Woven EndoBridge (WEB) system for the treatment of wide-necked bifurcation aneurysms: final 12-month results of the pivotal WEB Intrasaccular Therapy (WEB-IT) Study. J Neurointerv Surg. 11:924-930

6. Baxter BW, Rosso D, Lownie SP (1998) Double microcatheter technique for detachable coil treatment of large, wide-necked intracranial aneurysms. AJNR Am J Neuroradiol 19:1176-1178

7. Bebawy JF, Gupta DK, Bendok BR, Hemmer LB, Zeeni C, Avram MJ, Batjer HH, Koht A (2010) Adenosine-induced flow arrest to facilitate intracranial aneurysm clip ligation: doseresponse data and safety profile. Anesth Analg 110:1406-1411
8. Bechan RS, Sprengers ME, Majoie CB, Peluso JP, Sluzewski M, van Rooij WJ (2016) Stent-assisted coil embolization of intracranial aneurysms: complications in acutely ruptured versus unruptured aneurysms. AJNR Am J Neuroradiol 37:502-507

9. Benech CA, Perez R, Faccani G, Trompeo AC, Cavallo S, Beninati S, Berardino M (2014) Adenosine-induced cardiac arrest in complex cerebral aneurysms surgery: an Italian single-center experience. J Neurosurg Sci 58:87-94

10. Brilstra EH, Rinkel GJ (2002) Treatment of ruptured intracranial aneurysms by embolization with controlled detachable coils. Neurologist 8:35-40

11. Brilstra EH, Rinkel GJ, van der Graaf Y, van Rooij WJ, Algra A (1999) Treatment of intracranial aneurysms by embolization with coils: a systematic review. Stroke 30:470-476

12. Brisman JL, Roonprapunt C, Song JK, Niimi Y, Setton A, Berenstein A, Flamm ES (2004) Intentional partial coil occlusion followed by delayed clip application to wide-necked middle cerebral artery aneurysms in patients presenting with severe vasospasm. Report of two cases, J Neurosurg 101:154-158

13. Brown RD, Broderick JP (2014) Unruptured intracranial aneurysms: epidemiology, natural history, management options, and familial screening. Lancet Neurol 13:393-404

14. Bulters DO, Santarius T, Chia HL, Parker RA, Trivedi R, Kirkpatrick PJ, Kirollos RW (2011) Causes of neurological deficits following clipping of 200 consecutive ruptured aneurysms in patients with good-grade aneurysmal subarachnoid haemorrhage. Acta Neurochir (Wien) 153:295-303

15. Campi A, Ramzi N, Molyneux AJ, Summers PE, Kerr RS, Sneade M, Yarnold JA, Rischmiller J, Byrne JV (2007) Retreatment of ruptured cerebral aneurysms in patients randomized by coiling or clipping in the International Subarachnoid Aneurysm Trial (ISAT). Stroke 38:1538-1544

16. Cantore G, Santoro A, Guidetti G, Delfinis CP, Colonnese C, Passacantilli E (2008) Surgical treatment of giant intracranial aneurysms: current viewpoint. Neurosurgery. 63:279-289 (discussion 289-290)

17. Cekirge HS, Yavuz K, Geyik S, Saatci I (2011) HyperForm balloon remodeling in the endovascular treatment of anterior cerebral, middle cerebral, and anterior communicating artery aneurysms: clinical and angiographic follow-up results in 800 consecutive patients. J Neurosurg 114:944-953

18. Chaturvedi S, Sohrab S, Tselis A (2001) Carotid stent thrombosis: report of 2 fatal cases. Stroke 32:2700-2702

19. Chen ML, Gupta A, Chatterjee A, Khazanova D, Dou E, Patel H, Gialdini G, Merkler AE, Navi BB, Kamel H (2018) Association between unruptured intracranial aneurysms and downstream stroke. Stroke 49:2029-2033

20. Choudhri O, Mukerji N, Steinberg GK (2013) Combined endovascular and microsurgical management of complex cerebral aneurysms. Front Neurol 4:108

21. Cockroft KM, Marks MP, Steinberg GK (2000) Planned direct dual-modality treatment of complex broad-necked intracranial aneurysms: four technical case reports. Neurosurgery 46:226230 (discussion 230-221)

22. Cognard C, Weill A, Spelle L, Piotin M, Castaings L, Rey A, Moret J (1999) Long-term angiographic follow-up of 169 intracranial berry aneurysms occluded with detachable coils. Radiology 212:348-356

23. Crobeddu E, Lanzino G, Kallmes DF, Cloft HJ (2013) Review of 2 decades of aneurysm-recurrence literature, part 1: reducing recurrence after endovascular coiling. AJNR Am J Neuroradiol 34:266-270

24. Crowell RM, Yasargil MG (1973) End-to-side anastomosis of superficial temporal artery to middle cerebral artery branch in the dog. Neurochirurgia 16:73-77 
25. D’Urso PI, Lanzino G, Cloft HJ, Kallmes DF (2011) Flow diversion for intracranial aneurysms: a review. Stroke 42:2363-2368

26. Dandy WE (1938) Intracranial aneurysm of the internal carotid artery: cured by operation. Ann Surg 107:654-659

27. Darflinger RJ, Chao K (2015) Using the barrel technique with the LVIS Jr (low-profile visualized intraluminal support) stent to treat a wide neck MCA bifurcation aneurysm. J Vasc Interv Neurol 8:25-27

28. Desai VR, Rosas AL, Britz GW (2017) Adenosine to facilitate the clipping of cerebral aneurysms: literature review. Stroke Vasc Neurol 2:204-209

29. Dewan MC, Rattani A, Fieggen G, Arraez MA, Servadei F, Boop FA, Johnson WD, Warf BC, Park KB (2018) Global neurosurgery: the current capacity and deficit in the provision of essential neurosurgical care. Executive Summary of the Global Neurosurgery Initiative at the Program in Global Surgery and Social Change. J Neurosurg 130:1039-1408

30. Dossani RH, Patra DP, Kosty J, Jumah F, Kuybu O, Mohammed N, Waqas M, Riaz M, Cuellar H (2019) Early versus delayed flow diversion for ruptured intracranial aneurysms: a meta-analysis. World Neurosurg 126:41-52

31. Dott NM (1933) Intracranial aneurysms: cerebral arterio-radiography: surgical treatment. Edinb Med J 40:T219-T240

32. Familiari P, Maldaner N, Kursumovic A, Rath SA, Vajkoczy P, Raco A, Dengler J, G.I.A.S. Group (2015) Cost comparison of surgical and endovascular treatment of unruptured giant intracranial aneurysms. Neurosurgery 77:733-741 (discussion 741-733)

33. Ferns SP, Sprengers ME, van Rooij WJ, Rinkel GJ, van Rijn JC, Bipat S, Sluzewski M, Majoie CB (2009) Coiling of intracranial aneurysms: a systematic review on initial occlusion and reopening and retreatment rates. Stroke 40:e523-529

34. Fiorella D, Gache L, Frame D, Arthur AS (2020) How safe and effective are flow diverters for the treatment of unruptured small/ medium intracranial aneurysms of the internal carotid artery? Meta-analysis for evidence-based performance goals. J Neurointerv Surg 12:869-873

35. Fukada J, Morishita K, Satou H, Shiiku C, Koshino T, Abe T (1998) Surgical removal of a stent entrapped in the left main coronary artery. Ann Thorac Cardiovasc Surg 4:162-163

36. Gory B, Spiotta AM, Mangiafico S, Consoli A, Biondi A, Pomero E, Killer-Oberpfalzer M, Weber W, Riva R, Labeyrie PE, Turjman F (2016) PulseRider stent-assisted coiling of wide-neck bifurcation aneurysms: periprocedural results in an international series. AJNR Am J Neuroradiol 37:130-135

37. Greving JP, Wermer MJ, Brown RD, Morita A, Juvela S, Yonekura M, Ishibashi T, Torner JC, Nakayama T, Rinkel GJ, Algra A (2014) Development of the PHASES score for prediction of risk of rupture of intracranial aneurysms: a pooled analysis of six prospective cohort studies. Lancet Neurol 13:59-66

38. Grunwald IQ, Papanagiotou P, Struffert T, Politi M, Krick C, Gül G, Reith W (2007) Recanalization after endovascular treatment of intracerebral aneurysms. Neuroradiology 49:41-47

39. Guinn NR, McDonagh DL, Borel CO, Wright DR, Zomorodi AR, Powers CJ, Warner DS, Lam AM, Britz GW (2011) Adenosine-induced transient asystole for intracranial aneurysm surgery: a retrospective review. J Neurosurg Anesthesiol 23:35-40

40. Henkes H, Fischer S, Liebig T, Weber W, Reinartz J, Miloslavski E, Kühne D (2008) Repeated endovascular coil occlusion in 350 of 2759 intracranial aneurysms: safety and effectiveness aspects. Neurosurgery 62:1532-1537

41. Higashida RT, Smith W, Gress D, Urwin R, Dowd CF, Balousek PA, Halbach VV (1997) Intravascular stent and endovascular coil placement for a ruptured fusiform aneurysm of the basilar artery Case report and review of the literature. $\mathrm{J}$ Neurosurg 87:944-949
42. Holmes DR, Savage M, LaBlanche JM, Grip L, Serruys PW, Fitzgerald P, Fischman D, Goldberg S, Brinker JA, Zeiher AM, Shapiro LM, Willerson J, Davis BR, Ferguson JJ, Popma J, King SB, Lincoff AM, Tcheng JE, Chan R, Granett JR, Poland M (2002) Results of Prevention of REStenosis with Tranilast and its Outcomes (PRESTO) trial. Circulation 106:1243-1250

43. Intarakhao P, Thiarawat P, Rezai Jahromi B, Kozyrev DA, Teo MK, Choque-Velasquez J, Luostarinen T, Hernesniemi J (2018) Adenosine-induced cardiac arrest as an alternative to temporary clipping during intracranial aneurysm surgery. J Neurosurg 129:684-690

44. I.S.o.U.I.A. Investigators (1998) Unruptured intracranial aneurysms-risk of rupture and risks of surgical intervention. N Engl J Med 339:1725-1733

45. Ishishita $Y$, Tanikawa R, Noda K, Kubota H, Izumi N, Katsuno M, Ota N, Miyazaki T, Hashimoto M, Kimura T, Morita A (2014) Universal extracranial-intracranial graft bypass for large or giant internal carotid aneurysms: techniques and results in 38 consecutive patients. World Neurosurg 82:130-139

46. Jafar JJ, Russell SM, Woo HH (2002) Treatment of giant intracranial aneurysms with saphenous vein extracranial-to-intracranial bypass grafting: indications, operative technique, and results in 29 patients. Neurosurgery 51:138-144 (discussion 144-136)

47. Kai Y, Hamada J, Morioka M, Yano S, Kuratsu J (2005) Evaluation of the stability of small ruptured aneurysms with a small neck after embolization with Guglielmi detachable coils: correlation between coil packing ratio and coil compaction. Neurosurgery 56:785-792 (discussion 785-792)

48. Kalani MY, Zabramski JM, Hu YC, Spetzler RF (2013) Extracranial-intracranial bypass and vessel occlusion for the treatment of unclippable giant middle cerebral artery aneurysms. Neurosurgery 72:428-435 (discussion 435-426)

49. Kawanabe Y, Sadato A, Taki W, Hashimoto N (2001) Endovascular occlusion of intracranial aneurysms with Guglielmi detachable coils: correlation between coil packing density and coil compaction. Acta Neurochir (Wien) 143:451-455

50. Khan SA, McDonagh DL, Adogwa O, Gokhale S, Toche UN, Verla T, Zomorodi AR, Britz GW (2014) Perioperative cardiac complications and 30-day mortality in patients undergoing intracranial aneurysmal surgery with adenosine-induced flow arrest: a retrospective comparative study. Neurosurgery 74:267271 (discussion 271-262)

51. Kocaeli H, Andaluz N, Choutka O, Zuccarello M (2008) Use of radial artery grafts in extracranial-intracranial revascularization procedures. Neurosurg Focus 24:E5

52. Kwon OK, Kim SH, Kwon BJ, Kang HS, Kim JH, Oh CW, Han MH (2005) Endovascular treatment of wide-necked aneurysms by using two microcatheters: techniques and outcomes in 25 patients. AJNR Am J Neuroradiol 26:894-900

53. Kwon SC, Ding YH, Dai D, Kadirvel R, Lewis DA, Kallmes DF (2011) Preliminary results of the luna aneurysm embolization system in a rabbit model: a new intrasaccular aneurysm occlusion device. AJNR Am J Neuroradiol 32:602-606

54. Kwon SC, Shin YS, Kim HS, Kim SY (2006) A double catheter technique for elongated middle cerebral artery bifurcation aneurysm. A case report. Interv Neuroradiol 12:41-44

55. Lane B, Bohnstedt BN, Cohen-Gadol AA (2015) A prospective comparative study of microscope-integrated intraoperative fluorescein and indocyanine videoangiography for clip ligation of complex cerebral aneurysms. J Neurosurg 122:618-626

56. Lecler A, Raymond J, Rodriguez-Régent C, Al Shareef F, Trystram D, Godon-Hardy S, Ben Hassen W, Meder JF, Oppenheim C, Naggara ON (2015) Intracranial aneurysms: recurrences more than 10 years after endovascular treatment-a prospective cohort study, systematic review, and meta-analysis. Radiology 277:173-180 
57. Lee KS, Zhang JJY, Alalade AF, Vine R, Lanzino G, Park N, Roberts G, Gurusinghe NT (2020) Radiological surveillance of small unruptured intracranial aneurysms: a systematic review, meta-analysis, and meta-regression of 8428 aneurysms. Neurosurg Rev. https://doi.org/10.1007/s10143-020-01420-1

58. Lee KS, Zhang JJY, Bolem N, Leong ML, Goh CP, Hassan R, Salek AAM, Sein Lwin APT, Teo K, Chou N, Nga V, Yeo TT (2020) Freehand insertion of external ventricular drainage catheter: evaluation of accuracy in a single center. Asian J Neurosurg $15: 45-50$

59. Lemole GM Jr, Henn J, Javedan S, Deshmukh V, Spetzler RF (2002) Cerebral revascularization performed using posterior inferior cerebellar artery-posterior inferior cerebellar artery bypass. Report of four cases and literature review. J Neurosurg 97:219-223

60. Li H, Pan R, Wang H, Rong X, Yin Z, Milgrom DP, Shi X, Tang Y, Peng Y (2013) Clipping versus coiling for ruptured intracranial aneurysms: a systematic review and meta-analysis. Stroke 44:29-37

61. Li MH, Chen SW, Li YD, Chen YC, Cheng YS, Hu DJ, Tan HQ, Wu Q, Wang W, Sun ZK, Wei XE, Zhang JY, Qiao RH, Zong WH, Zhang Y, Lou W, Chen ZY, Zhu Y, Peng DR, Ding SX, Xu XF, Hou XH, Jia WP (2013) Prevalence of unruptured cerebral aneurysms in Chinese adults aged 35 to 75 years: a cross-sectional study. Ann Intern Med 159:514-521

62. Liebig T, Kabbasch C, Strasilla C, Berlis A, Weber W, Pierot L, Patankar T, Barreau X, Dervin J, Kursumovic A, Rath S, Lubicz B, Klisch J (2015) Intrasaccular flow disruption in acutely ruptured aneurysms: a multicenter retrospective review of the use of the WEB. AJNR Am J Neuroradiol 36:1721-1727

63. Lindgren A, Vergouwen MD, van der Schaaf I, Algra A, Wermer M, Clarke MJ, Rinkel GJ (2018) Endovascular coiling versus neurosurgical clipping for people with aneurysmal subarachnoid haemorrhage, Cochrane Database Syst Rev 8 CD003085

64. Linskey ME, Jungreis CA, Yonas H, Hirsch WL, Sekhar LN, Horton JA, Janosky JE (1994) Stroke risk after abrupt internal carotid artery sacrifice: accuracy of preoperative assessment with balloon test occlusion and stable xenon-enhanced CT. AJNR Am J Neuroradiol 15:829-843

65 Locksley HB (1966) Natural history of subarachnoid hemorrhage, intracranial aneurysms and arteriovenous malformations. Based on 6368 cases in the cooperative study. J Neurosurg 25:219-239

66. Louw DF, Asfora WT, Sutherland GR (2001) A brief history of aneurysm clips. Neurosurg Focus 11:E4

67. Lubicz B, Klisch J, Gauvrit JY, Szikora I, Leonardi M, Liebig T, Nuzzi NP, Boccardi E, Paola FD, Holtmannspotter M, Weber W, Calgliari E, Sychra V, Mine B, Pierot L (2014) WEB-DL endovascular treatment of wide-neck bifurcation aneurysms: short- and midterm results in a European study. AJNR Am J Neuroradiol 35:432-438

68 Luostarinen T, Takala RS, Niemi TT, Katila AJ, Niemelä M, Hernesniemi J, Randell T (2010) Adenosine-induced cardiac arrest during intraoperative cerebral aneurysm rupture. World Neurosurg. 73:79-83 (discussion e79)

69. Madaelil TP, Moran CJ, Cross DT, Kansagra AP (2017) Flow diversion in ruptured intracranial aneurysms: a meta-analysis. AJNR Am J Neuroradiol 38:590-595

70. Manning NW, Cheung A, Phillips TJ, Wenderoth JD (2019) Pipeline shield with single antiplatelet therapy in aneurysmal subarachnoid haemorrhage: multicentre experience. J Neurointerv Surg 11:694-698

71. Mocco J, Fargen KM, Albuquerque FC, Bendok BR, Boulos AS, Carpenter JS, Fiorella DJ, Hoh BL, Howington JU, Liebman KM, Natarajan SK, Rai AT, Rodriguez-Mercado R, Siddiqui AH, Snyder KV, Veznedaroglu E, Hopkins LN, Levy EI (2011) Delayed thrombosis or stenosis following enterprise-assisted stent-coiling: is it safe? Midterm results of the interstate collaboration of enterprise stent coiling, Neurosurgery 69:908-913 (discussion 913-904)

72 Moe KS, Bergeron CM, Ellenbogen RG (2010) Transorbital neuroendoscopic surgery. Neurosurgery 67:ons16-28

73. Molyneux AJ, Kerr RS, Yu LM, Clarke M, Sneade M, Yarnold JA, Sandercock P, International Subarachnoid Aneurysm Trial (ISAT) Collaborative Group (2005) International subarachnoid aneurysm trial (ISAT) of neurosurgical clipping versus endovascular coiling in 2143 patients with ruptured intracranial aneurysms: a randomised comparison of effects on survival, dependency, seizures, rebleeding, subgroups, and aneurysm occlusion. Lancet 366:809-817

74. Moret J, Cognard C, Weill A, Castaings L, Rey A (1997) The "remodelling technique" in the treatment of wide neck intracranial aneurysms. Angiographic Results and Clinical Follow-up in 56 Cases. Interventional neuroradiology: journal of peritherapeutic neuroradiology, surgical procedures and related neurosciences 3:21-35

75. Nishido H, Piotin M, Bartolini B, Pistocchi S, Redjem H, Blanc R (2014) Analysis of complications and recurrences of aneurysm coiling with special emphasis on the stent-assisted technique. AJNR Am J Neuroradiol 35:339-344

76. Oishi H, Nonaka S, Yamamoto M, Arai H (2013) Feasibility and efficacy of endovascular therapy for ruptured distal anterior cerebral artery aneurysms. Neurol Med Chir 53:304-309

77. Ormond DR, Hadjipanayis CG (2013) The supraorbital keyhole craniotomy through an eyebrow incision: its origins and evolution. Minim Invasive Surg 2013:296469

78. Otani T, Nakamura M, Fujinaka T, Hirata M, Kuroda J, Shibano K, Wada S (2013) Computational fluid dynamics of blood flow in coil-embolized aneurysms: effect of packing density on flow stagnation in an idealized geometry. Med Biol Eng Comput 51:901-910

79. Papagiannaki C, Spelle L, Januel AC, Benaissa A, Gauvrit JY, Costalat V, Desal H, Turjman F, Velasco S, Barreau X, Courtheoux P, Cognard C, Herbreteau D, Moret J, Pierot L (2014) WEB intrasaccular flow disruptor-prospective, multicenter experience in 83 patients with 85 aneurysms. AJNR Am J Neuroradiol 35:2106-2111

80. Park KB, Johnson WD, Dempsey RJ (2016) Global neurosurgery: the unmet need. World Neurosurg 88:32-35

81. Park KY, Kim BM, Lim YC, Chung J, Kim DJ, Joo JY, Huh SK, Kim DI, Lee KC, Lee JW (2015) The role of endovascular treatment for ruptured distal anterior cerebral artery aneurysms: comparison with microsurgical clipping. J Neuroimaging 25:81-86

82. Patel HC, Teo M, Higgins N, Kirkpatrick PJ (2010) High flow extra-cranial to intra-cranial bypass for complex internal carotid aneurysms. Br J Neurosurg 24:173-178

83. Phan K, Huo YR, Jia F, Phan S, Rao PJ, Mobbs RJ, Mortimer AM (2016) Meta-analysis of stent-assisted coiling versus coilingonly for the treatment of intracranial aneurysms. J Clin Neurosci $31: 15-22$

84. Pierot L, Klisch J, Cognard C, Szikora I, Mine B, Kadziolka K, Sychra V, Gubucz I, Januel AC, Lubicz B (2013) Endovascular WEB flow disruption in middle cerebral artery aneurysms: preliminary feasibility, clinical, and anatomical results in a multicenter study. Neurosurgery 73:27-34 (discussion 34-25)

85. Pierot L, Spelle L, Leclerc X, Cognard C, Bonafe A, Moret J (2009) Endovascular treatment of unruptured intracranial aneurysms: comparison of safety of remodeling technique and standard treatment with coils. Radiology 251:846-855

86. Pierot L, Spelle L, Molyneux A, Byrne J (2016) Clinical and anatomical follow-up in patients with aneurysms treated with the WEB device: 1-year follow-up report in the cumulated 
population of 2 prospective, multicenter series (WEBCAST and French Observatory). Neurosurgery 78:133-141

87. Pierot L, Spelle L, Molyneux A, Byrne J, W.a.F.O. Investigators (2016) Clinical and anatomical follow-up in patients with aneurysms treated with the WEB device: 1-year follow-up report in the cumulated population of 2 prospective, multicenter series (WEBCAST and French Observatory). Neurosurgery 78:133-141

88. Piotin M, Biondi A, Sourour N, Mounayer C, Jaworski M, Mangiafico S, Andersson T, Söderman M, Goffette P, Anxionnat R, Blanc R (2018) The LUNA aneurysm embolization system for intracranial aneurysm treatment: short-term, mid-term and long-term clinical and angiographic results. J NeuroInterv Surg 10:e34

89. Piotin M, Spelle L, Mounayer C, Salles-Rezende MT, GiansanteAbud D, Vanzin-Santos R, Moret J (2007) Intracranial aneurysms: treatment with bare platinum coils-aneurysm packing, complex coils, and angiographic recurrence. Radiology 243:500-508

90. Pool JL, Housepian EM (1960) Temporary clip occlusion of major cerebral arteries during intracranial aneurysm surgery: clinical and postmortem data. Surg Forum 10:791-794

91. Pranata R, Yonas E, Vania R, Sidipratomo P, July J (2021) Efficacy and safety of PulseRider for treatment of wide-necked intracranial aneurysm-a systematic review and meta-analysis. Interv Neuroradiol 27:60-67

92. Raabe A, Nakaji P, Beck J, Kim LJ, Hsu FP, Kamerman JD, Seifert V, Spetzler RF (2005) Prospective evaluation of surgical microscope-integrated intraoperative near-infrared indocyanine green videoangiography during aneurysm surgery. J Neurosurg 103:982-989

93. Radovanovic I, Abou-Hamden A, Bacigaluppi S, Tymianski M (2014) A safety, length of stay, and cost analysis of minimally invasive microsurgery for anterior circulation aneurysms. Acta Neurochir (Wien) 156:493-503

94. Rajah G, Narayanan S, Rangel-Castilla L (2017) Update on flow diverters for the endovascular management of cerebral aneurysms. Neurosurg Focus 42:E2

95. Raymond J, Guilbert F, Weill A, Georganos SA, Juravsky L, Lambert A, Lamoureux J, Chagnon M, Roy D (2003) Long-term angiographic recurrences after selective endovascular treatment of aneurysms with detachable coils. Stroke 34:1398-1403

96. Ries T, Siemonsen S, Thomalla G, Grzyska U, Zeumer H, Fiehler J (2007) Long-term follow-up of cerebral aneurysms after endovascular therapy prediction and outcome of retreatment. AJNR Am J Neuroradiol 28:1755-1761

97. Rouchaud A, Brinjikji W, Lanzino G, Cloft HJ, Kadirvel R, Kallmes DF (2016) Delayed hemorrhagic complications after flow diversion for intracranial aneurysms: a literature overview. Neuroradiology 58:171-177

98. Sader E, Yee P, Hodaie M (2017) Assessing barriers to neurosurgical care in sub-Saharan Africa: the role of resources and infrastructure. World Neurosurg 98:682-688.e683

99. Sanai N, Zador Z, Lawton MT (2009) Bypass surgery for complex brain aneurysms: an assessment of intracranial-intracranial bypass. Neurosurgery 65:670-683 (discussion 683)

100. Sani S, Lopes DK (2005) Treatment of a middle cerebral artery bifurcation aneurysm using a double neuroform stent "Y" configuration and coil embolization: technical case report. Neurosurgery 57:E209 (discussion E209)

101. Sekhar LN, Duff JM, Kalavakonda C, Olding M (2001) Cerebral revascularization using radial artery grafts for the treatment of complex intracranial aneurysms: techniques and outcomes for 17 patients. Neurosurgery 49:646-658 (discussion 658-649)

102. Sharma M, Ambekar S, Ahmed O, Nixon M, Sharma A, Nanda A, Guthikonda B (2014) The utility and limitations of intraoperative near-infrared indocyanine green videoangiography in aneurysm surgery. World Neurosurg 82:e607-613

103. Shi X, Qian H, Fang T, Zhang Y, Sun Y, Liu F (2015) Management of complex intracranial aneurysms with bypass surgery: a technique application and experience in 93 patients. Neurosurg Rev 38:109-119 (discussion 119-120)

104. Shin YS, Kim DI, Lee SI, Chung JI, Yoon PH, Lee KC (2000) The usefulness of the new "double-catheter technique" in the treatment of parent artery incorporated wide-necked aneurysm with guglielmi detachable coils. Technical notes. Interv Neuroradiol 6:61-64

105. Sia SF, Morgan MK (2013) High flow extracranial-to-intracranial brain bypass surgery. J Clin Neurosci 20:1-5

106. Sluzewski M, van Rooij WJ, Rinkel GJ, Wijnalda D (2003) Endovascular treatment of ruptured intracranial aneurysms with detachable coils: long-term clinical and serial angiographic results. Radiology 227:720-724

107. Soize S, Gawlitza M, Raoult H, Pierot L (2016) Imaging followup of intracranial aneurysms treated by endovascular means: why, when, and how? Stroke 47:1407-1412

108. Sorenson TJ, Iacobucci M, Murad MH, Spelle L, Moret J, Lanzino G (2019) The pCONUS bifurcation aneurysm implants for endovascular treatment of adults with intracranial aneurysms: a systematic review and meta-analysis. Surg Neurol Int 10:24

109. Spetzler RF, McDougall CG, Albuquerque FC, Zabramski JM, Hills NK, Partovi S, Nakaji P, Wallace RC (2013) The Barrow Ruptured Aneurysm Trial: 3-year results. J Neurosurg 119:146-157

110. Spetzler RF, McDougall CG, Zabramski JM, Albuquerque FC, Hills NK, Nakaji P, Karis JP, Wallace RC (2019) Ten-year analysis of saccular aneurysms in the Barrow Ruptured Aneurysm Trial. J Neurosurg 132:771-776.

111. Spetzler RF, McDougall CG, Zabramski JM, Albuquerque FC, Hills NK, Russin JJ, Partovi S, Nakaji P, Wallace RC (2015) The Barrow Ruptured Aneurysm Trial: 6-year results. J Neurosurg 123:609-617

112. Spetzler RF, Selman W, Carter LP (1984) Elective EC-IC bypass for unclippable intracranial aneurysms. Neurol Res 6:64-68

113. Spetzler RF, Zabramski JM, McDougall CG, Albuquerque FC, Hills NK, Wallace RC, Nakaji P (2018) Analysis of saccular aneurysms in the Barrow Ruptured Aneurysm Trial. J Neurosurg 128:120-125

114. Sughrue ME, Saloner D, Rayz VL, Lawton MT (2011) Giant intracranial aneurysms: evolution of management in a contemporary surgical series. Neurosurgery 69:1261-1270 (discussion 1270-1261)

115. Sundt TM Jr, Piepgras DG, Marsh WR, Fode NC (1986) Saphenous vein bypass grafts for giant aneurysms and intracranial occlusive disease. J Neurosurg 65:439-450

116. Suzuki S, Kurata A, Yamada M, Iwamoto K, Nakahara K, Sato K, Niki J, Sasaki M, Kitahara T, Fujii K, Kan S (2011) Outcomes analysis of ruptured distal anterior cerebral artery aneurysms treated by endosaccular embolization and surgical clipping. Interv Neuroradiol 17:49-57

117. Tajsic T, Cullen J, Guilfoyle M, Helmy A, Kirollos R, Kirkpatrick P, Trivedi R (2019) Indocyanine green fluorescence video angiography reduces vascular injury-related morbidity during micro-neurosurgical clipping of ruptured cerebral aneurysms: a retrospective observational study. Acta Neurochir (Wien) 161:2397-2401

118. Tanabe J, Ishikawa T, Moroi J (2017) Safe time duration for temporary middle cerebral artery occlusion in aneurysm surgery based on motor-evoked potential monitoring. Surg Neurol Int 8:79

119. Teo M, Guilfoyle MR, Turner C, Kirkpatrick PJ, STASH Collaborators (2017) What factors determine treatment outcome in aneurysmal subarachnoid hemorrhage in the modern era? A post hoc STASH analysis. World Neurosurg 105:270-281 
120. Thompson BG, Brown RD, Amin-Hanjani S, Broderick JP, Cockroft KM, Connolly ES, Duckwiler GR, Harris CC, Howard VJ, Johnston SC, Meyers PM, Molyneux A, Ogilvy CS, Ringer AJ, Torner J, C.u.o.C.a.S.N, American Heart Association Stroke Council, and Council on Epidemiology and Prevention, A.H. Association, A.S. Association (2015) Guidelines for the management of patients with unruptured intracranial aneurysms: a guideline for healthcare professionals from the American Heart Association/American Stroke Association. Stroke 46:2368-2400

121 Todd MM, Hindman BJ, Clarke WR, Torner JC, I.H.f.A.S.T.I. Investigators (2005) Mild intraoperative hypothermia during surgery for intracranial aneurysm. N Engl J Med 352:135-145

122. Trager AL, Sadasivan C, Seong J, Lieber BB (2009) Correlation between angiographic and particle image velocimetry quantifications of flow diverters in an in vitro model of elastase-induced rabbit aneurysms. J Biomech Eng 131:034506

123. Vallee JN, Aymard A, Vicaut E, Reis M, Merland JJ (2003) Endovascular treatment of basilar tip aneurysms with Guglielmi detachable coils: predictors of immediate and long-term results with multivariate analysis 6-year experience. Radiology 226:867-879

124 van Doormaal TP, van der Zwan A, Verweij BH, Langer DJ, Tulleken CA (2006) Treatment of giant and large internal carotid artery aneurysms with a high-flow replacement bypass using the excimer laser-assisted nonocclusive anastomosis technique. Neurosurgery 59:ONS328-334 (discussion ONS334-325)

125. van Gijn J, Kerr RS, Rinkel GJ (2007) Subarachnoid haemorrhage. Lancet 369:306-318

126. van Rooij SBT, van Rooij WJ, Peluso JP, Sluzewski M, Bechan RS, Kortman HG, Beute GN, van der Pol B, Majoie CB (2017) WEB treatment of ruptured intracranial aneurysms: a single-center cohort of 100 patients. AJNR Am J Neuroradiol 38:2282-2287

127. Vlak MH, Algra A, Brandenburg R, Rinkel GJ (2011) Prevalence of unruptured intracranial aneurysms, with emphasis on sex, age, comorbidity, country, and time period: a systematic review and meta-analysis. Lancet Neurol 10:626-636

128. Waldron JS, Halbach VV, Lawton MT (2009) Microsurgical management of incompletely coiled and recurrent aneurysms: trends, techniques, and observations on coil extrusion. Neurosurgery. 64:301-315 (discussion 315-307)

129. Wallace AN, Kayan Y, Delgado Almandoz JE, Fease JL, Milner AA, Scholz JM (2019) Endovascular treatment of widenecked intracranial aneurysms with the scepter XC balloon catheter, with low-profile visualized intraluminal support (LVIS) Jr. deployment as a "Bailout" technique. World Neurosurg 121:e798-e807

130. Wallace AN, Samaniego E, Kayan Y, Derdeyn CP, Delgado Almandoz JE, Dandapat S, Fease JL, Thomas M, Milner AM, Scholz JM, Ortega-Gutierrez S (2019) Balloon-assisted coiling of cerebral aneurysms with the dual-lumen Scepter XC balloon catheter: experience at two high-volume centers. Interv Neuroradiol 25:414-418

131. Washington CW, Zipfel GJ, Chicoine MR, Derdeyn CP, Rich KM, Moran CJ, Cross DT, Dacey RG Jr (2013) Comparing indocyanine green videoangiography to the gold standard of intraoperative digital subtraction angiography used in aneurysm surgery. J Neurosurg 118:420-427

132. Wiebers DO, Whisnant JP, Huston J, Meissner I, Brown RD, Piepgras DG, Forbes GS, Thielen K, Nichols D, O'Fallon WM, Peacock J, Jaeger L, Kassell NF, Kongable-Beckman GL, Torner JC, I.S.o.U.I.A. Investigators, (2003) Unruptured intracranial aneurysms: natural history, clinical outcome, and risks of surgical and endovascular treatment. Lancet 362:103-110

133. Yasargil MG, Antic J, Laciga R, Jain KK, Hodosh RM, Smith RD (1976) Microsurgical pterional approach to aneurysms of the basilar bifurcation. Surg Neurol 6:83-91

134. Yasargil MG, Fox JL (1975) The microsurgical approach to intracranial aneurysms. Surg Neurol 3:7-14

135. Yin L, Wei M, Ren H (2016) Double microcatheter technique for coil embolization of small aneurysms with unfavorable configurations: a comparative study of the aneurysms that are $\leq 3 \mathrm{~mm}$ or $>3 \mathrm{~mm}$. Interv Neuroradiol 22:158-164

136. Yoon KW, Kim YJ (2010) In-stent stenosis of stent assisted endovascular treatment on intracranial complex aneurysms. J Korean Neurosurg Soc 48:485-489

137. Yundt KD, Grubb RL, Diringer MN, Powers WJ (1997) Cerebral hemodynamic and metabolic changes caused by brain retraction after aneurysmal subarachnoid hemorrhage. Neurosurgery 40:442

138. Zhang JJY, Wang S, Foo ASC, Yang M, Quah BL, Sun IS, Ng ZX, Teo K, Pang BC, Yang EW, Lwin S, Chou N, Low SW, Yeo TT, Santarius T, Nga VDW (2019) Outcomes of subdural versus subperiosteal drain after burr-hole evacuation of chronic subdural hematoma: a multicenter cohort study. World Neurosurg 131:e392-e401

139. Zhang M, Anzai H, Chopard B, Ohta M (2016) Towards the patient-specific design of flow diverters made from helix-like wires: an optimization study. Biomed Eng Online 15:159

140. Zhang X, Li L, Hong B, Xu Y, Liu Y, Huang Q, Liu J (2018) A systematic review and meta-analysis on economic comparison between endovascular coiling versus neurosurgical clipping for ruptured intracranial aneurysms. World Neurosurg 113:269-275

141. Zhao J, Farhatnia Y, Kalaskar DM, Zhang Y, Bulter PEM, Seifalian AM (2015) The influence of porosity on the hemocompatibility of polyhedral oligomeric silsesquioxane poly (caprolactone-urea) urethane. Int J Biochem Cell Biol 68:176-186

142. Zhao J, Lin H, Summers R, Yang M, Cousins BG, Tsui J (2018) Current treatment strategies for intracranial aneurysms: an overview. Angiology 69:17-30

143. Zheng F, Dong Y, Xia P, Mpotsaris A, Stavrinou P, Brinker G, Goldbrunner R, Krischek B (2017) Is clipping better than coiling in the treatment of patients with oculomotor nerve palsies induced by posterior communicating artery aneurysms? A systematic review and meta-analysis. Clin Neurol Neurosurg 153:20-26

Publisher's Note Springer Nature remains neutral with regard to jurisdictional claims in published maps and institutional affiliations. 